\title{
On the search for the right definition of heart failure with preserved ejection fraction
}

\author{
Agnieszka Kapłon-Cieślicka ${ }^{1,2}$, Karolina Kupczyńska ${ }^{1,3}$, Piotr Dobrowolski, ${ }^{1,}$, \\ Błażej Michalski ${ }^{1,3}$, Miłosz J. Jaguszewski ${ }^{1,5}$, Waldemar Banasiak ${ }^{1,6}$, Paweł Burchardt ${ }^{1,7,8}$, \\ Łukasz Chrzanowski ${ }^{1,3}$, Szymon Darocha ${ }^{1,9}$, Justyna Domienik-Karłowicz ${ }^{1,10}$, \\ Jarosław Drożd ${ }^{1,11}$, Marcin Fijałkowski ${ }^{1,5}$, Krzysztof J. Filipiak ${ }^{1,2}$, Marcin Gruchała ${ }^{1,5}$, \\ Ewa A. Jankowska ${ }^{1,12,13}$, Piotr Jankowski ${ }^{1,14}$, Jarosław D. Kasprzak ${ }^{1,3}$, \\ Wojciech Kosmala $^{1,13,15}$, Piotr Lipiec ${ }^{1,16}$, Przemysław Mitkowski ${ }^{1,17}$, \\ Katarzyna Mizia-Stec, ${ }^{18}$, Piotr Szymański1 ${ }^{1,}$, Agnieszka Tycińska ${ }^{1,20}$, Wojciech Wańha ${ }^{1,21}$, \\ Maciej Wybraniec ${ }^{1,18}$, Adam Witkowski ${ }^{1,22}$, Piotr Ponikowski ${ }^{1,12,13}$, \\ on behalf of "Club 30" of the Polish Cardiac Society \\ "Club 30", Polish Cardiac Society, Poland \\ ${ }^{2} 1^{\text {st }}$ Chair and Department of Cardiology, Medical University of Warsaw, Poland \\ ${ }^{3} 1^{\text {st }}$ Department and Chair of Cardiology, Medical University of Lodz, Poland \\ ${ }^{4}$ Department of Hypertension, National Institute of Cardiology, Warsaw, Poland \\ ${ }^{5} 1^{\text {st }}$ Department of Cardiology, Medical University of Gdansk, Poland \\ ${ }^{6}$ Department of Cardiology, $4^{\text {th }}$ Military Hospital, Wroclaw, Poland \\ ${ }^{7}$ Department of Hypertension, Angiology, and Internal Medicine, \\ Poznan University of Medical Sciences, Poznan, Poland \\ ${ }^{8}$ Department of Cardiology, J. Strus Hospital, Poznan, Poland \\ ${ }^{9}$ Department of Pulmonary Circulation, Thromboembolic Diseases and Cardiology, \\ Center of Postgraduate Medical Education, Otwock, Poland \\ ${ }^{10}$ Department of Internal Medicine and Cardiology, Medical University of Warsaw, Poland \\ ${ }^{11}$ Department of Cardiology, Medical University of Lodz, Poland \\ ${ }^{12}$ Department of Heart Diseases, Wroclaw Medical University, Wroclaw, Poland \\ ${ }^{13}$ Center for Heart Diseases, University Hospital, Wroclaw, Poland \\ ${ }^{14} 1^{\text {st }}$ Department of Cardiology, Interventional Electrocardiology and Hypertension, Institute of Cardiology, \\ Jagiellonian University Medical College, Krakow, Poland \\ ${ }^{15}$ Chair and Department of Cardiology, Wroclaw Medical University, Wroclaw, Poland \\ ${ }^{16}$ Department of Rapid Cardiac Diagnostics, Chair of Cardiology, Medical University of Lodz, Poland \\ ${ }^{17} 1^{\text {st }}$ Department of Cardiology, Chair of Cardiology, \\ Karol Marcinkowski University of Medical Sciences, Poznan, Poland \\ ${ }^{18} 1^{\text {st }}$ Department of Cardiology, School of Medicine in Katowice, \\ Medical University of Silesia, Katowice, Poland \\ ${ }^{19}$ Center of Postgraduate Medical Education, Central Clinical Hospital \\ of the Ministry of the Interior in Warsaw, Poland \\ ${ }^{20}$ Department of Cardiology, Medical University of Bialystok, Poland \\ ${ }^{21}$ Department of Cardiology and Structural Heart Diseases, Medical University of Silesia, Katowice, Poland \\ ${ }^{22}$ Department of Interventional Cardiology and Angiology, National Institute of Cardiology, Warsaw, Poland
}

Address for correspondence: Agnieszka Kapłon-Cieślicka, MD, PhD, $1^{\text {st }}$ Chair and Department of Cardiology,

Medical University of Warsaw, ul. Banacha 1a, 02-097 Warszawa, Poland, tel: +48 22 5992958, fax: +48 22 5991957, e-mail: agnieszka.kaplon@gmail.com

Received: $16.07 .2020 \quad$ Accepted: 10.09 .2020 


\begin{abstract}
The definition of heart failure with preserved ejection fraction (HFpEF) has evolved from a clinically based "diagnosis of exclusion" to definitions focused on objective evidence of diastolic dysfunction and/ lor elevated left ventricular filling pressures. Despite advances in our understanding of HFpEF pathophysiology and the development of more sophisticated imaging modalities, the diagnosis of HFpEF remains challenging, especially in the chronic setting, given that symptoms are provoked by exertion and diagnostic evaluation is largely conducted at rest. Invasive hemodynamic study, and in particular invasive exercise testing, is considered the reference method for HFDEF diagnosis. However, its use is limited as opposed to the high number of patients with suspected HFpEF. Thus, diagnostic criteria for $H F p E F$ should be principally based on non-invasive measurements. As no single non-invasive variable can adequately corroborate or refute the diagnosis, different combinations of clinical, echocardiographic, and/or biochemical parameters have been introduced. Recent years have brought an abundance of HF$p E F$ definitions. Here, we present and compare four of them: 1) the 2016 European Society of Cardiology criteria for HFpEF; 2) the 2016 echocardiographic algorithm for diagnosing diastolic dysfunction; 3) the 2018 evidence-based $H_{2} F P E F$ score; and 4) the most recent, 2019 Heart Failure Association HFA-PEFF algorithm. These definitions vary in their approach to diagnosis, as well as sensitivity and specificity. Further studies to validate and compare the diagnostic accuracy of HFpEF definitions are warranted. Nevertheless, it seems that the best HFpEF definition would originate from a randomized clinical trial showing a favorable effect of an intervention on prognosis in HFpEF. (Cardiol J 2020; 27, 5: 449-468)
\end{abstract}

Key words: diagnosis, diastolic function, E/e' ratio, left atrial pressure, pulmonary capillary wedge pressure, natriuretic peptides, atrial fibrillation

\section{Introduction}

Heart failure with preserved ejection fraction (HFpEF) is one of the hot topics in modern cardiology. Entering "HFpEF", "diastolic dysfunction", or related terms into the MEDLINE (Medical Literature Analysis and Retrieval System Online) database results in over 12,000 citations, with a sharp increase in recent years. Despite well-defined demographic and clinical characteristics of $\mathrm{HFpEF}$ patients, as well as ongoing research and discussion on the essence of HFpEF, no uniform diagnostic criteria have been widely accepted, nor has any treatment been shown to improve prognosis [1]. Different definitions have been proposed by scientific societies or adopted in randomized clinical trials [1-11]. These definitions vary greatly in their approach to the diagnosis (clinically based vs. focused on objective evidence of diastolic dysfunction and/or elevated left ventricular [LV] filling pressure, with different combinations of parameters used in each definition), which may reflect limitations of our understanding of $\mathrm{HFpEF}$ pathophysiology but also different stages of $\mathrm{HFpEF}$ continuum with some definitions aiming at preclinical diastolic dysfunction, and some directed at clinically overt, advanced HFpEF (Fig. 1) [12, 13]. In everyday clinical practice, confirming or excluding $\mathrm{HFpEF}$ poses a considerable challenge with a potential for both overdiagnosis (mostly in primary care and in patients hospitalized for acute dyspnea) and underdiagnosis (especially in stable, uncongested, elderly patients with exertional symptoms) [14-24]. The abundance of HFpEF definitions might cause even more confusion among non-HF specialists. This article is an attempt to present the most up-to-date diagnostic criteria for chronic HFpEF, compare different definitions, and summarize their strengths and limitations.

\section{Why is it difficult to establish diagnostic criteria for $\mathrm{HFpEF}$ ?}

As shown in Figure 1, different diagnostic parameters reflect different pathomechanisms and different stages of HFpEF. Furthermore, most parameters are not specific for HFpEF (Table 1 [4, 24-47]). Thus, no single variable, echocardiographic or biochemical, can adequately corroborate or refute the diagnosis $[4,5]$. Moreover, for different parameters, no clear cut-off points can be defined because most of them are continuously distributed within a population and may vary depending on age, gender, body surface area, body mass index (BMI), heart rhythm, kidney function, and the presence of cardiac and extra-cardiac comorbidities [5]. Notably, choosing a "lower" value as a threshold for diagnosis would increase 


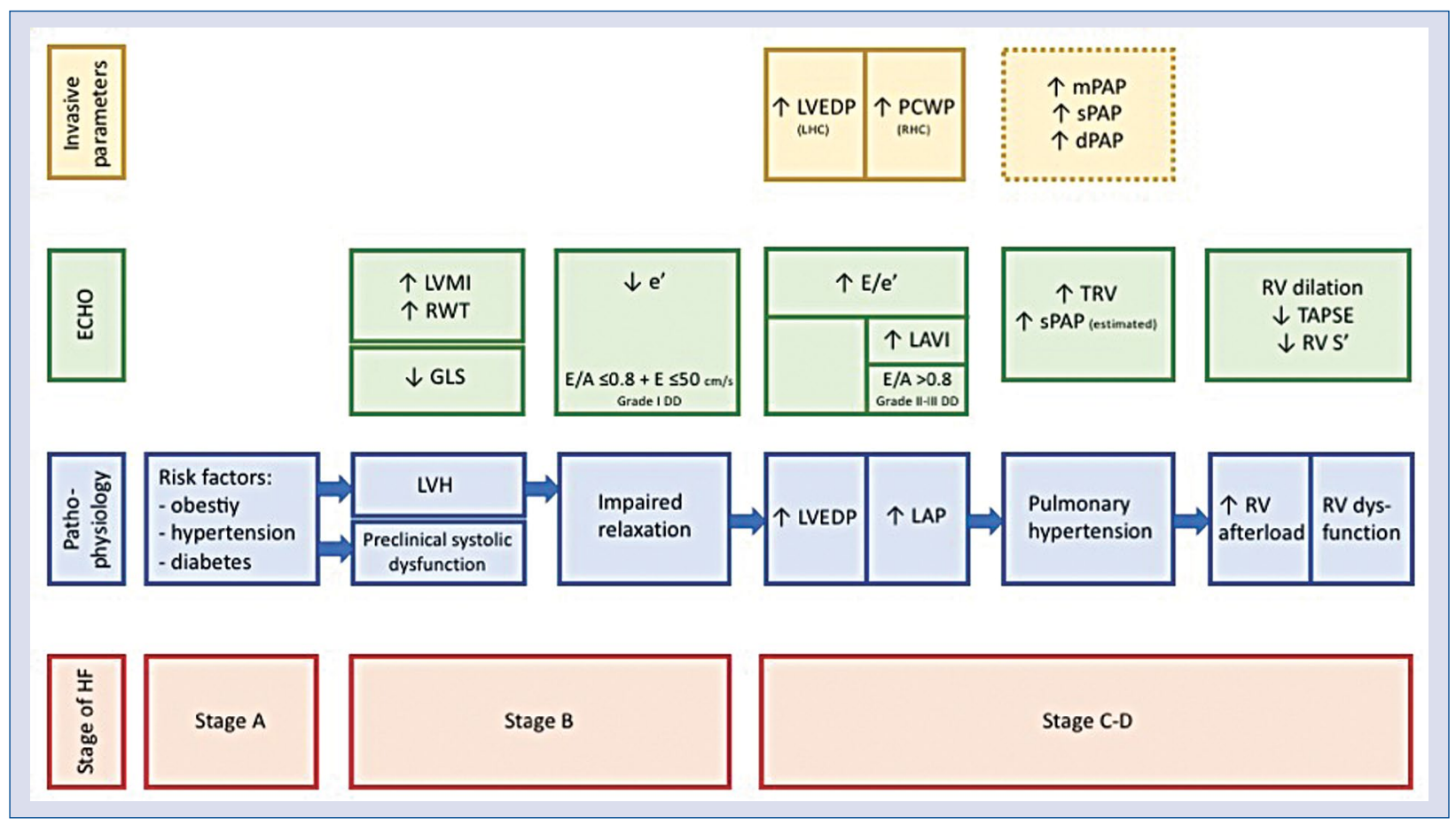

Figure 1. Natural history of heart failure with preserved ejection fraction (HFpEF) with corresponding echocardiographic and invasively measured parameters. For clarity and to enhance educational value, separate pathophysiological stages have been distinguished with parameters allocated to each stage. In reality, these stages overlap and can change with time, volume status, and level of physical activity. The diagram does not include more sophisticated echocardiographic and invasive parameters, and it does not refer to all postulated pathomechanisms (such as microvascular inflammation or cardiometabolic abnormalities). Dotted line indicates parameters (measured during right heart catheterization $[\mathrm{RHC}]$ ) that do not constitute criteria for the diagnosis of HFpEF by any definition. Stages of HF according to the American College of Cardiology Foundation (ACCF) and the American Heart Association (AHA) have been shown [2]; DD — diastolic dysfunction; dPAP — diastolic pulmonary artery pressure; GLS - global longitudinal strain; HF - heart failure; LAP — left atrial pressure; LAVI — left atrial volume index; LHC — left heart catheterization; LVEDP - left ventricular end-diastolic pressure; LVH - left ventricular hypertrophy; LVMI — left ventricular mass index; mPAP — mean pulmonary artery pressure; PCWP — pulmonary capillary wedge pressure; RV — right ventricle; RWT — relative wall thickness; sPAP — systolic pulmonary artery pressure; TAPSE — tricuspid annular plane systolic excursion; TRV — tricuspid regurgitation velocity.

Table 1. Factors affecting natriuretic peptides and chosen echocardiographic parameters assessed in the course of a diagnostic work-up for heart failure with preserved ejection fraction.

\begin{tabular}{|c|c|c|}
\hline Parameter & $\begin{array}{l}\text { Pathophysiologic rationale } \\
\text { and clinical significance }\end{array}$ & Limitations and confounding factors \\
\hline NPs & $\begin{array}{l}\text { The main trigger for release is increased LV } \\
\text { end-diastolic wall stress }\end{array}$ & $\begin{array}{l}\text { 1. In chronic HFpEF, NPs can be false negative: } \\
\text { - NPs are more sensitive for HFrEF: LV wall } \\
\text { stress is proportional to LV radius and in- } \\
\text { versely proportional to LV wall thickness } \\
\text { therefore NP levels are lower in HFpEF } \\
\text { (hypertrophic, non-dilated LV) than in HFrEF } \\
\text { (dilated LV); LV hypertrophy in HFpEF } \\
\text { develops to reduce wall stress } \\
\text { - NPs are more sensitive for acute HF } \\
\text { - Obesity and female gender are associated } \\
\text { with lower NPs } \\
\text { 2. NPs can be false positive in the absence } \\
\text { of HFpEF: } \\
\text { - Older age, AF, kidney disease, valvular heart } \\
\text { disease, pulmonary disease, and arterial } \\
\text { pulmonary hypertension can result in } \\
\text { elevated NPs } \\
\text { 3. NP levels can fluctuate in time }\end{array}$ \\
\hline
\end{tabular}


Table 1 (cont.). Factors affecting natriuretic peptides and chosen echocardiographic parameters assessed in the course of a diagnostic work-up for heart failure with preserved ejection fraction.

\begin{tabular}{|c|c|c|}
\hline Parameter & $\begin{array}{l}\text { Pathophysiologic rationale } \\
\text { and clinical significance }\end{array}$ & Limitations and confounding factors \\
\hline \multicolumn{3}{|c|}{ Echocardiographic parameters } \\
\hline $\begin{array}{l}\mathrm{e}^{\prime} \text { (septal } \\
\text { and lateral) }\end{array}$ & $\mathrm{e}^{\prime}$ reflects $L V$ relaxation & $\begin{array}{l}\text { - Measurement is angle-dependent } \\
\text { - e' decreases with age } \\
\text { - e' is unreliable in patients with mitral annu- } \\
\text { lar calcifications or prosthetic valves or rings } \\
\text { - e' can be influenced by regional wall motion } \\
\text { abnormalities due to myocardial ischemia } \\
\text { - TDI-derived parameters are much less } \\
\text { preload-dependent than mitral inflow; } \\
\text { however, e' may increase with increased } \\
\text { preload, mainly in subjects with normal LV } \\
\text { function } \\
\text { - in healthy subjects, e' also increases with } \\
\text { exercise-induced tachycardia }\end{array}$ \\
\hline$E$ and $E / A$ & $\begin{array}{l}\text { The } E \text { wave reflects } L A-L V \text { pressure gradient } \\
\text { during early diastole, which depends on LA } \\
\text { pressure and LV relaxation/LV stiffness }\end{array}$ & $\begin{array}{l}\text { - E velocity is highly dependent on preload } \\
\text { - tachycardia affects E velocity and can lead } \\
\text { to fusion of E/A waves } \\
\text { - E/A ratio not applicable in AF } \\
\text { - E/A ratio is age-dependent } \\
\text { - without additional variables normal and } \\
\text { pseudonormal mitral inflow pattern are } \\
\text { difficult to differentiate } \\
\text { - increased E velocity and pseudonormal/re- } \\
\text { strictive mitral inflow pattern can be second- } \\
\text { ary to other causes, including in particular } \\
\text { moderate-to-severe mitral regurgitation, } \\
\text { volume overload (e.g. in kidney disease), } \\
\text { constrictive pericarditis, etc. }\end{array}$ \\
\hline $\mathrm{E} / \mathrm{e}^{\prime}$ & $\begin{array}{l}\text { The most appropriate echocardiographic } \\
\text { parameter reflecting LV filling pressure: } \\
-E / e^{\prime} \geq 15 \text { has a high positive predictive } \\
\text { value for elevated PCWP } \\
\text { - E/e' is less dependent on: } \\
\text { - preload than } E \text { and } e^{\prime} \text { velocities } \\
\text { - heart rate than E velocity } \\
\text { - age than } e^{\prime} \text { velocity }\end{array}$ & $\begin{array}{l}\text { - Correlation with invasive measurements is } \\
\text { moderate with a "grey zone" for intermedi- } \\
\text { ate values of 9-14 }\end{array}$ \\
\hline LAVI & $\begin{array}{l}\text { Enlarged LA reflects longstanding elevation } \\
\text { of LA pressure }\end{array}$ & $\begin{array}{l}\text { - LA enlargement can be secondary to other } \\
\text { causes, including in particular AF, mitral } \\
\text { valve diseases, volume overload (e.g. in } \\
\text { kidney disease), etc. (reduced specificity) } \\
\text { - LA enlargement develops with time and } \\
\text { can be absent at an early stage of HFpEF } \\
\text { (reduced sensitivity) }\end{array}$ \\
\hline $\begin{array}{l}\text { TRV and } \\
\text { sPAP }\end{array}$ & $\begin{array}{l}\text { TRV is used for estimation of: } \\
\text { - echocardiographic probability of pulmonary } \\
\text { hypertension (as per } 2015 \text { ESC/ERS } \\
\text { guidelines) } \\
\text { - SPAP using simplified Bernoulli equation: } \\
\text { SPAP }=4 \times \mathrm{TRV}^{2}+\text { estimated right atrial } \\
\text { pressure }\end{array}$ & $\begin{array}{l}\text { - Correlation with invasive measurements } \\
\text { is moderate } \\
\text { — TRV measurement may be difficult or } \\
\text { impossible (e.g. in the case of absent or } \\
\text { trivial tricuspid regurgitation or suboptimal } \\
\text { acoustic window) } \\
\text { - TRV and echocardiographically estimated } \\
\text { sPAP increase with age } \\
\text { - TRV is preload dependent } \\
\text { - increase in TRV and SPAP can be secondary } \\
\text { to other causes, including left heart disease } \\
\text { other than HFpEF, pulmonary disease, } \\
\text { pulmonary embolism and chronic } \\
\text { thromboembolic pulmonary hypertension, } \\
\text { pulmonary arterial hypertension, fluid } \\
\text { overload, etc. } \\
\text { - massive TR can result in low systolic RV-RA } \\
\text { pressure gradient (low TRV) leading to } \\
\text { underestimation of sPAP }\end{array}$ \\
\hline
\end{tabular}

Based on references: [4, 24-47]. AF — atrial fibrillation; ERS - European Respiratory Society; ESC - European Society of Cardiology; HF - heart failure; HFpEF — heart failure with preserved ejection fraction; HFrEF — heart failure with reduced ejection fraction; LA - left atrium; LV - left ventricle; NP — natriuretic peptide; PCWP - pulmonary capillary wedge pressure; RA — right atrium; RV - right ventricle; SPAP - systolic pulmonary artery pressure; TDI — tissue Doppler imaging; TR — tricuspid regurgitation; TRV — tricuspid regurgitation velocity 
sensitivity at the expense of lower specificity, while setting a "higher" threshold would increase specificity at the expense of lower sensitivity. Thus, establishing cut-offs for echocardiographic variables and natriuretic peptides (NPs), though based on comparisons with invasive measurements, is inevitably arbitrary. The above considerations regarding adoption of cut-off points refer even to the "gold standard" of HFpEF diagnosis - heart catheterization $[48,49]$. Invasive hemodynamic assessment is considered a reference investigation for diagnosing $\mathrm{HFpEF}[5,12,28]$. However, it has limited availability compared to the large number of patients requiring diagnostic evaluation for this highly prevalent disease. Other limitations include unknown reproducibility and a questionable risk/benefit ratio of an invasive study in view of the lack of specific HFpEF treatment [12, 49]. Hence, ideally, in most patients, diagnosis should be made based on non-invasive testing. However, validation of NPs and echocardiographic indices of HFpEF shows their relatively poor correlation with invasive hemodynamic measurements $[4,24-30$, $39,44-46,50]$. Among different echocardiographic variables, the $\mathrm{E} / \mathrm{e}$ ' ratio is considered the most appropriate for approximation of LV filling pressures, but its agreement with invasive measurements is only moderate [24-30]. Similarly, echocardiographic estimation of pulmonary artery pressure is not very accurate compared to right heart catheterization (RHC) [44-46]. This, again, explains the need for an algorithm including a combination of different non-invasive variables rather than a single parameter to diagnose $\mathrm{HFpEF}$.

Another problem is that NP concentrations as well as echocardiographic indices of diastolic function and left atrial (LA) pressure can change in time, and therefore a single measurement of a given parameter does not provide definitive conclusions. Repeated measurements of NPs can show up to $100 \%$ variability in concentration in an individual patient $[5,40]$. Mitral inflow velocities, tricuspid regurgitation velocity (TRV), and to a lesser extent LA volume index (LAVI) and e' velocities can also change over time depending on preload and/or heart rate [31-34, 41-47]. Another issue regarding echocardiographic measurements would be intra- and interobserver variability [51-53]. Importantly, in chronic HFpEF, symptoms are observed during physical exertion, and thus measurements obtained at rest can lead to false negative results. Most non-invasive HFpEF definitions refer to assessment at rest with the possibility to proceed to exercise echocardiography if the results are inconclusive or if the risk is deemed intermediate $[1,4,5]$. Notably, when invasive exercise testing was implemented as a reference method, among patients finally diagnosed with $\mathrm{HFpEF}$, almost half displayed elevation in pulmonary capillary wedge pressure (PCWP) only during exercise [24, 54]. This indicates that even the "gold standard" of $\mathrm{HFpEF}$ diagnosis, invasive hemodynamic study, can yield a high proportion of false negative results if performed only at rest.

The aforementioned problems are mirrored by a relatively poor agreement between different HFpEF diagnostic criteria: a patient diagnosed with $\mathrm{HFpEF}$ according to one definition, may be reclassified as not having $\mathrm{HFpEF}$ according to another [19, 21-24, 55]. Moreover, non-invasive $\mathrm{HFpEF}$ definitions vary significantly in their accuracy in identifying patients with invasively proven $\mathrm{HFpEF}$, as well as in their predictive value for future cardiovascular events [19, 20-24, 55]. It seems that the best "validation" of a HFpEF definition would be a positive result of a randomized clinical trial showing a favorable effect of an intervention on prognosis in $\mathrm{HFpEF}$ - inclusion criteria in such a trial could automatically become diagnostic criteria for HFpEF.

\section{The first step towards a modern definition: The 2016 ESC guidelines}

The 2016 European Society of Cardiology (ESC) HF guidelines were revolutionary by distinguishing three clinical syndromes: $\mathrm{HF}$ with reduced (HFrEF), preserved (HFpEF), and midrange ejection fraction $(\mathrm{EF})$, with an unequivocal definition of each of these clinical entities [1]. The diagnosis of chronic HFpEF in a patient with an EF of $\geq 50 \%$ required the presence of HF symptoms and/or signs, elevation of NPs (B-type NP [BNP] $\geq 35 \mathrm{pg} / \mathrm{mL}$ or N-terminal pro-BNP [NT-proBNP] $\geq 125 \mathrm{pg} / \mathrm{mL}$ ), and at least one of the following echocardiographic criteria: LA enlargement (LAVI $>34 \mathrm{~mL} / \mathrm{m}^{2}$ ), LV hypertrophy (by LV mass index [LVMI]), or diastolic dysfunction (by E/e' ratio and e') [1]. Given the low specificity of LA enlargement and NP exclusionary cut-off points adopted in the guidelines, those criteria could be perceived as relatively "mild" with some potential for overdiagnosis. However, it seems reasonable for a new definition to include a wider spectrum of patients facilitating their accurate characterization and a thorough analysis to identify more specific subgroups. On the other hand, the definition itself was based on assessment at rest, which, in patients 
with exertional symptoms, may have led to false negative results. In fact, in well compensated patients with $\mathrm{HFpEF}$ confirmed by invasive exercise testing, its sensitivity was found to be only $60 \%$ and specificity $75 \%$ [24].

\section{An echocardiographic algorithm for the diagnosis of diastolic dysfunction: The 2016 ASE/EACVI recommendations}

In 2016, less than two months after the release of the ESC guidelines on HF, the American Society of Echocardiography (ASE) and the European Association of Cardiovascular Imaging (EACVI) published recommendations on the echocardiographic evaluation of diastolic function (an update of a previous document from 2009) [4, 56]. A simple algorithm was proposed for echocardiographic assessment of diastolic function in patients with an $\mathrm{EF}$ of $\geq 50 \%$ (Fig. 2A). The algorithm was based on four easily obtainable echocardiographic parameters: two tissue Doppler imaging (TDI)derived, direct indices of $\mathrm{LV}$ diastolic dysfunction (reduced e' velocity and increased E/e' ratio) and two "indirect" parameters secondary to elevation of LA pressure (increased LAVI and TRV) [4]. Compared to the ESC guidelines, the ASE/EACVI algorithm did not account for LV hypertrophy nor, understandably, NP concentrations. Nevertheless, it was more specific for diastolic dysfunction, due to the requirement of three or four positive criteria to satisfy the definition, compared to only one positive echocardiographic criterion required to meet the ESC definition $[1,4,24]$. The ASE/EACVI algorithm also enabled echocardiographic estimation of LA pressure and grading of diastolic dysfunction based largely on mitral inflow pattern (Fig. 2B) [4]. In patients with dyspnea and grade I diastolic dysfunction (normal estimated LA pressure at rest), exercise echocardiography was recommended [4]. Importantly, the ASE/EACVI algorithm is the only one among the four discussed in this document which is designed for identifying and grading diastolic dysfunction rather than diagnosing $\mathrm{HFpEF}$ as a clinical syndrome.

The ASE/EACVI algorithm was validated against invasive measurements in a few studies, with sensitivity for elevation of resting LV filling pressures ranging from $69 \%$ to $87 \%$ and specificity ranging from $74 \%$ to $88 \%$, which was significantly superior to clinical assessment [21-23]. However, when validated against invasive exercise testing, its sensitivity dropped to $34 \%$ (maintaining a high specificity of 83\%) [24].

\section{Evidence-based assessment of HFpEF probability: The $2018 \mathrm{H}_{2} \mathrm{FPEF}$ score}

Contrary to other HFpEF definitions based on expert consensus opinion, the $\mathrm{H}_{2} \mathrm{FPEF}$ score was derived from a cohort of 414 patients with an EF of $\geq 50 \%$, who were referred for exercise $\mathrm{RHC}$ for unexplained dyspnea in Mayo Clinic (Rochester, MN, USA) [54]. The $\mathrm{H}_{2} \mathrm{FPEF}$ score includes six dichotomized, widely available variables (four clinical and two echocardiographic), which, if positive, are attributed one point, with the exception of atrial fibrillation (AF) and obesity (BMI of $>30$ $\mathrm{kg} / \mathrm{m}^{2}$ ), which are attributed three and two points, respectively (Table 2). Thus, the maximum score is nine points. For each score, the probability of invasively confirmed $\mathrm{HFpEF}$ was calculated, allowing justifiable exclusion of $\mathrm{HFpEF}$ in patients with total scores of $0-1$, and establishing its diagnosis with reasonably high confidence (likelihood of $>90 \%$ ) at scores of 6-9 [54].

In the original study, the $\mathrm{H}_{2} \mathrm{FPEF}$ score proved superior to the 2016 ESC definition, allowing accurate discrimination of $\mathrm{HFpEF}$ from noncardiac causes of dyspnea with area under the curve (AUC) in the receiver operating characteristic (ROC) analysis of 0.84 and 0.89 in the derivation and validation cohort, respectively [54]. Interestingly, inclusion of NT-proBNP cut-off points did not incrementally add diagnostic ability to the score [54]. This again confirms that, contrary to acute symptom exacerbation, in ambulatory patients with stable, exertional dyspnea, the discriminative value of NP measurements for HFpEF is relatively low because chronic HFpEF patients may have low NP concentrations, and patients with normal LV diastolic function can have elevated NPs due to AF or other comorbidities [35-40].

In subsequent studies, the $\mathrm{H}_{2} \mathrm{FPEF}$ score showed high sensitivity for clinically ascertained diagnosis of $\mathrm{HFpEF}$, as well as predictive value for future HF-related events both in HFpEF and in non-HF patients with cardiovascular risk factors [57-60].

\section{A comprehensive, stepwise approach to diagnosis: The 2019 HFA-PEFF algorithm}

In 2019, the Heart Failure Association (HFA) of the ESC released a consensus recommendation for the diagnosis of $\mathrm{HFpEF}$ [5]. The proposed HFA-PEFF algorithm, presented in Figure 3, is a stepwise approach, including: 


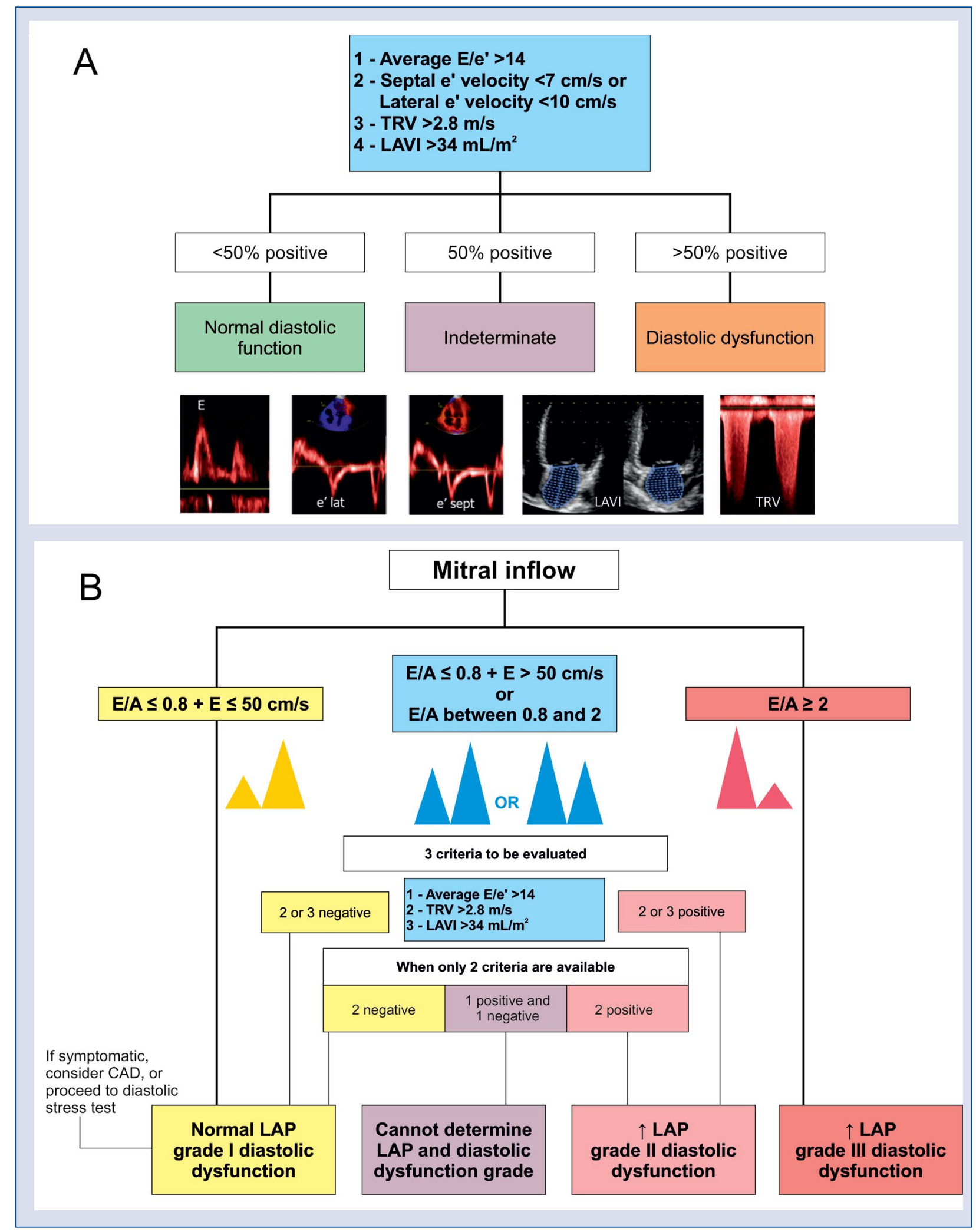

Figure 2. The 2016 American Society of Echocardiography/European Association of Cardiovascular Imaging (ASE/ /EACVI) diagnostic algorithm for: A. The diagnosis of diastolic dysfunction in patients with preserved ejection fraction, B. Grading of diastolic dysfunction and estimation of left atrial pressure (LAP) in patients with preserved ejection fraction and myocardial disease. Adopted from Nagueh et al., 2016 [4], modified; CAD — coronary artery disease; LAVI — left atrial volume index; TRV — tricuspid regurgitation velocity. 
Table 2. The $\mathrm{H}_{2}$ FPEF score. Adopted from Reddy et al., 2018 [54], modified.

\begin{tabular}{lccc}
\hline & Clinical variable & Value & Points \\
\hline $\mathbf{H}_{2}$ & Heavy & BMI $>30 \mathrm{~kg} / \mathrm{m}^{2}$ & 2 \\
& Hypertensive & 2 or more antihypertensive medicines & 1 \\
$\mathbf{F}$ & Atrial Fibrillation & Paroxysmal or persistent & 3 \\
$\mathbf{P}$ & Pulmonary Hypertension & sPAP $>35 \mathrm{mmHg}^{*}$ & 1 \\
E & Elder & Age $>60$ years & 1 \\
F & Filling Pressure & E/e' $>9^{*}$ & 1 \\
H $_{2}$ FPEF score & & & Sum: $\mathbf{0 - 9}$ \\
\hline
\end{tabular}

*From Doppler echocardiography; BMI — body mass index; SPAP — systolic pulmonary artery pressure

- step 1 - $\mathbf{P}$ for Pretest assessment;

- step 2 - E for Echocardiographic and NP score;

- step $3-\mathbf{F}_{1}$ for Functional testing in case of uncertainty;

- step $4-\mathbf{F}_{2}$ for Final etiology.

\section{Step 1 (P): Pretest assessment}

This step is consistent with an initial diagnostic work-up of patients presenting with dyspnea or other symptoms suggestive of $\mathrm{HF}$, as recommended by the 2016 ESC guidelines on $\operatorname{HF}[1,5]$. Its goal is to identify individuals with potential diagnosis of HFpEF and exclude (or identify) alternative causes of symptoms (such as HFrEF, valvular disease, coronary artery disease, arrhythmias, pulmonary disease, anemia, etc.). This step encompasses clinical assessment, laboratory tests (including NPs if available), electrocardiogram, chest X-ray, and standard echocardiography. Clinical assessment includes evaluation of symptoms as well as risk factors for $\mathrm{HFpEF}$ (older age, obesity, arterial hypertension, metabolic syndrome with prediabetes/diabetes) and coexisting conditions. On the one hand, some comorbidities may imitate HF symptoms, and on the other hand, some are highly prevalent in $\mathrm{HFpEF}$ and thus strongly suggestive of $\mathrm{HFpEF}$, even if they could themselves explain exertional dyspnea (obesity, AF). If NP measurement is available, lower cut-off points (BNP of $35 \mathrm{pg} / \mathrm{mL}$ or NT-proBNP of $125 \mathrm{pg} / \mathrm{mL}$, consistent with the 2016 ESC guidelines on HF) are adopted in step 1 due to their higher sensitivity and negative predictive value $[1,5]$. Still, almost one fifth of patients with invasively proven $\mathrm{HFpEF}$ had NT-proBNP below this threshold, and thus normal NP concentrations do not exclude chronic HFpEF, especially in obese patients [24, 35-40]. Standard echocardiography aims to exclude alter- native cardiac causes of dyspnea, assess EF (with "preserved EF" defined as $\geq 50 \%$ ), and identify features suggestive of HFpEF, such as nondilated $\mathrm{LV}$ with concentric remodeling or hypertrophy, and LA enlargement. If step $1(\mathrm{P})$ indicates possible HFpEF, then step $2(\mathrm{E})$ is indicated [5].

\section{Step 2 (E): Echocardiographic and NP score}

Step 2 is based on the HFA-PEFF scoring system with 0-2 points assigned for each of the three domains: 1) functional (echocardiography), 2) morphological (echocardiography or, less frequently, cardiac magnetic resonance), and 3) biomarker (NPs). In each domain, cut-offs for certain parameters have been proposed and attributed one (minor criterion) or two points (major criterion), as shown in Table 3. Importantly, one domain can contribute maximally two points, even if more major or minor criteria are fulfilled. A total score of 5-6 points is considered to be diagnostic for HFpEF, while a score of $0-1$ points makes the diagnosis of HFpEF unlikely and should prompt assessment of other possible causes of symptoms. A score of 2-4 points requires further evaluation (step 3) using exercise testing (echocardiographic or invasive) [5].

In the HFA-PEFF score, different cut-offs for NPs and LAVI have been adopted for AF (vs. sinus rhythm), for e' for patients aged $\geq 75$ years (vs. younger patients), and, similarly to the ESC definition, for LVMI for women vs. men. For NPs, eight cut-off points are given: four for BNP and four for NT-proBNP, depending on heart rhythm (with cut-offs in AF three times higher than in sinus rhythm) and criterion type (major vs. minor) [5]. From the clinical perspective, the complexity of the score with multiple variables in each domain and diverse cut-off points for one variable might be considered a drawback hindering its use in eve- 


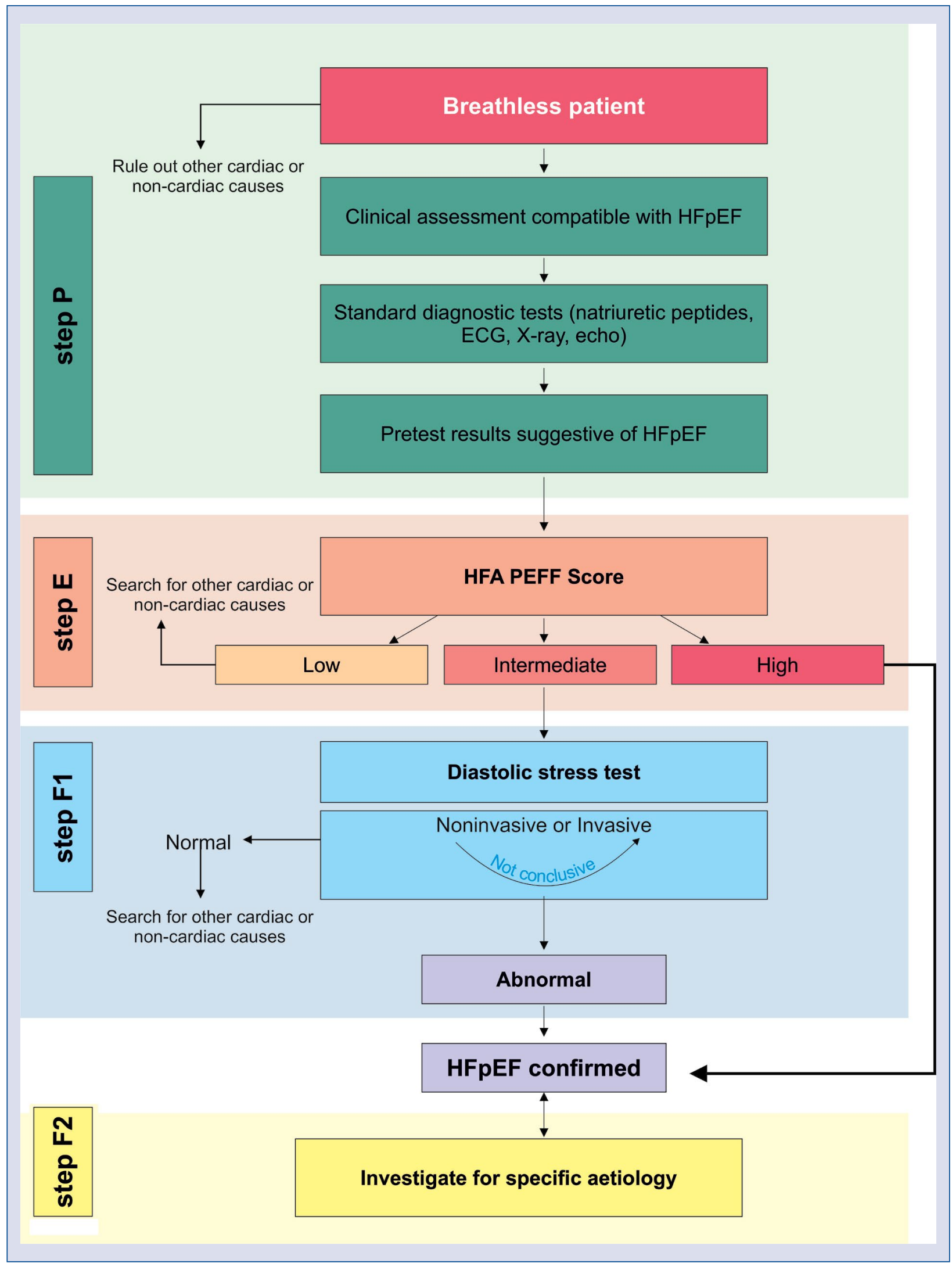

Figure 3. The HFA-PEFF diagnostic algorithm. Adopted from Pieske et al., 2019 [5], modified; HFpEF — heart failure with preserved ejection fraction; ECG - electrocardiogram. 
Table 3. The HFA-PEFF score (step 2 of the HFA-PEFF algorithm). Adopted from Pieske et al., 2019 [5], modified.

\begin{tabular}{|c|c|c|c|}
\hline & \multicolumn{3}{|c|}{ Domain } \\
\hline & Functional & Morphological & Biomarker \\
\hline 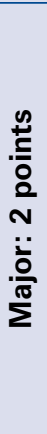 & $\begin{array}{l}\text { e': }^{\prime} \text { Age }<75 \text { years: } \\
\quad \text { Septal } \mathrm{e}^{\prime}<7 \mathrm{~cm} / \mathrm{s} \text { or } \\
\text { Lateral } \mathrm{e}^{\prime}<10 \mathrm{~cm} / \mathrm{s} \\
\text { Age } \geq 75 \text { years: } \\
\quad \text { Septal } \mathrm{e}^{\prime}<5 \mathrm{~cm} / \mathrm{s} \text { or } \\
\text { Lateral } \mathrm{e}^{\prime}<7 \mathrm{~cm} / \mathrm{s} \\
\text { or } \\
\text { Average E/e' } \geq 15 \\
\text { or } \\
\text { TRV }>2.8 \mathrm{~m} / \mathrm{s} \\
(\mathrm{sPAP}>35 \mathrm{mmHg})\end{array}$ & $\begin{array}{l}\text { LAVI: } \\
\qquad \begin{array}{l}\text { SR }>34 \mathrm{~mL} / \mathrm{m}^{2} \\
\text { AF }>40 \mathrm{~mL} / \mathrm{m}^{2}\end{array} \\
\text { or } \\
\text { RWT }>0.42 \text { and LVMI: } \\
\quad M \geq 149 \mathrm{~g} / \mathrm{m}^{2} \\
\quad W \geq 122 \mathrm{~g} / \mathrm{m}^{2}\end{array}$ & $\begin{array}{l}\text { NT-proBNP: } \\
\text { SR }>220 \mathrm{pg} / \mathrm{mL} \\
\text { AF }>660 \mathrm{pg} / \mathrm{mL} \\
\text { BNP: } \\
\text { SR }>80 \mathrm{pg} / \mathrm{mL} \\
\text { AF }>240 \mathrm{pg} / \mathrm{mL}\end{array}$ \\
\hline 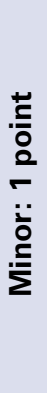 & $\begin{array}{l}\text { Average } E / e^{\prime} 9-14 \\
\text { or } \\
\text { GLS }<16 \%\end{array}$ & $\begin{array}{l}\text { LAVI: } \\
\quad \text { SR } 29-34 \mathrm{~mL} / \mathrm{m}^{2} \\
\text { AF } 34-40 \mathrm{~mL} / \mathrm{m}^{2} \\
\text { or } \\
\text { RWT }>0.42 \\
\text { or } \\
\text { LVMI: } \\
\quad \mathrm{M}>115 \mathrm{~g} / \mathrm{m}^{2},<149 \mathrm{~g} \\
\quad W>95 \mathrm{~g} / \mathrm{m}^{2},<122 \mathrm{~g} / \\
\text { or } \\
\text { LV wall thickness } \geq 12 \mathrm{n}\end{array}$ & $\begin{array}{l}\text { NT-proBNP: } \\
\text { SR } 125-220 \mathrm{pg} / \mathrm{mL} \\
\text { AF } 375-660 \mathrm{pg} / \mathrm{mL} \\
\text { BNP: } \\
\text { SR } 35-80 \mathrm{pg} / \mathrm{mL} \\
\text { AF } 105-240 \mathrm{pg} / \mathrm{mL}\end{array}$ \\
\hline \multicolumn{4}{|c|}{$\begin{array}{l}\text { Select only one score from each domain } \\
\text { Total score: } \\
0-1 \text { points: HFpEF unlikely } \rightarrow \text { search for alternative causes of symptoms } \\
\text { 2-4 points: intermediate probability } \rightarrow \text { diastolic stress test (non-invasive or invasive) } \\
\text { 5-6 points: HFpEF confirmed }\end{array}$} \\
\hline
\end{tabular}

$\mathrm{AF}$ - atrial fibrillation; BNP - B-type natriuretic peptide; GLS - global longitudinal strain; HFpEF - heart failure with preserved ejection fraction; LAVI - left atrial volume index; LVMI - left ventricular mass index; $\mathrm{M}$ - men; NT-proBNP - N-terminal proBNP; RWT - relative wall thickness; sPAP — systolic pulmonary artery pressure; SR - sinus rhythm; TRV — tricuspid regurgitation velocity; W - women

ryday practice. However, as stressed by the HFA Experts, not all parameters from each domain need to be available to calculate the score, and therefore the seeming abundance of parameters actually increases its practical utility because typically not all parameters are given in an echocardiographic report. Thus, HFpEF diagnosis actually requires only one major criterion from each domain (e.g. TRV $>2.8 \mathrm{~m} / \mathrm{s}$, LAVI $>40 \mathrm{~mL} / \mathrm{m}^{2}$, and NT-proBNP $>660 \mathrm{pg} / \mathrm{mL}$ for patients with AF) or two major criteria and one minor criterion (e.g. E/e' of $\geq 15$, LAVI $>34 \mathrm{~mL} / \mathrm{m}^{2}$, and NT-proBNP $125-220 \mathrm{pg} / \mathrm{mL}$ for patients with sinus rhythm). On the other hand, a definite exclusion of $\mathrm{HFpEF}$ would ideally necessitate evaluation of all parameters.

Notably, the HFA-PEFF score has, for the first time, included reduced absolute global longitudinal strain (GLS), an index of impaired systolic function, as a criterion for HFpEF diagnosis. Up to two thirds of HFpEF patients show abnormal GLS despite preserved EF [61, 62]. This reflects the complexity of HFpEF pathophysiology, with preclinical systolic dysfunction as yet another contributor to $\mathrm{HFpEF}$ syndrome [63-65].

The HFA-PEFF score was validated in two independent studies $[55,66]$. The first study included two prospective cohorts and showed excellent sensitivity (99\% for low-likelihood category, i.e. a total of $0-1$ points) and specificity (93\% for high-likelihood category, i.e. a total of $5-6$ points) of the score with an AUC of 0.90 [66]. However, final HFpEF diagnosis in this study was not based on invasive measurements but mostly on echocardiography, NPs, and clinical judgement. Furthermore, both cohorts included patients with high pre-test probability of $\mathrm{HFpEF}$ with only a small control group of non-HFpEF patients (potential selection bias). Notably, more than one third of patients in both cohorts were classified in the intermediatelikelihood category (a total of 2-4 points) with 
a need for step 3 of the HFA-PEFF algorithm to secure the diagnosis [66]. In the second study, the HFA-PEFF score was validated against exercise testing with invasive hemodynamic monitoring, showing only moderate accuracy, with an AUC of 0.73 [55]. One quarter of patients in whom HFpEF could have been ruled out based on the HFA-PEFF score (0-1 points) had elevated PCWP consistent with $\mathrm{HFpEF}$ diagnosis, and almost one fifth of patients deemed to have HFpEF by the score (5-6 points) had normal PCWP both at rest and during exercise [55].

\section{Step $3\left(\mathrm{~F}_{1}\right)$ : Functional testing} in the case of uncertainty

Step 3 is performed in patients who were attributed $2-4$ points in the HFA-PEFF score (step 2), and encompasses exercise echocardiography and/ /or heart catheterization at rest and during exercise. Exercise echocardiography (preferably using a semi-supine bicycle) can show an elevation in LV filling pressures (by E/e' ratio) during exertion, which can be accompanied by an increase in pulmonary artery pressure (estimated using TRV). An increase in the $\mathrm{E} / \mathrm{e}^{\prime}$ ratio to $\geq 15$ adds two points to the HFA-PEFF score calculated in step 2 . An increase in the $\mathrm{E} / \mathrm{e}^{\prime}$ ratio to $\geq 15$ with a peak TRV of $>3.4 \mathrm{~m} / \mathrm{s}$ adds three points to the HFA-PEFF score. A combined score from step 2 (E) and step $3\left(\mathrm{~F}_{1}\right)$ of five points or more confirms $\mathrm{HFpEF}$ diagnosis. If the combined score does not exceed five points, invasive hemodynamic assessment is recommended. This includes right and/or left heart catheterization at rest, and - in the case of inconclusive results - exercise RHC. Diagnostic criteria for $\mathrm{HFpEF}$ include resting LV end-diastolic pressure (LVEDP) of $\geq 16 \mathrm{mmHg}$ on left heart catheterization and/or mean PCWP of $\geq 15 \mathrm{mmHg}$ on RHC (of note, the cut-off point for PCWP is consistent with the 2016 ESC guidelines on HF but somewhat different from the threshold for postcapillary pulmonary hypertension adopted in the 2015 ESC guidelines on pulmonary hypertension [PCWP of $>15 \mathrm{mmHg}]$ ] $[1,5,46]$. Given that elevation of $\mathrm{LV}$ filling pressure may be present only during exertion, normal resting LVEDP or PCWP do not exclude HFpEF [24, 54]. In such patients, exercise RHC using cycle ergometry is recommended, and an increase of PCWP to $\geq 25 \mathrm{mmHg}$ is considered diagnostic for HFpEF [5]. The 2019 HFA consensus document does not refer to the possible role of acute volume challenge during $\mathrm{RHC}$ in establishing $\mathrm{HFpEF}$ diagnosis [46].

\section{Step $4\left(\mathrm{~F}_{2}\right)$ : Final etiology}

In most patients, $\mathrm{HFpEF}$ is associated with typical demographic and clinical presentation, and is related to common risk factors (older age, arterial hypertension, obesity, and metabolic syndrome), but in some patients HFpEF may be a manifestation of specific heart muscle diseases, for example hypertrophic cardiomyopathy, infiltrative cardiomyopathies (such as amyloidosis, sarcoidosis, or hemochromatosis), storage diseases (such as Fabry disease, glycogen storage diseases, or Gaucher disease), radiation-induced cardiomyopathy, endomyocardial fibrosis, autoimmune diseases, and other genetic disorders. Such specific etiologies need always to be considered, especially in cases with atypical presentation or positive family history, and if suspected, should prompt implementation of advanced diagnostic measures. Depending on the suspected underlying cause of $\mathrm{HFpEF}$, these might include cardiac magnetic resonance, $99 \mathrm{mTc}$ -DPD scintigraphy, positron emission tomography, cardiac or non-cardiac biopsies, and/or specific laboratory tests, including genetic testing [5].

\section{Is the 2016 ESC definition still valid?}

The 2016 ESC HFpEF definition was much more liberal and less specific than the 2019 criteria adopted by the HFA. The ESC definition required only one echocardiographic criterion to be fulfilled, and cut-off points for LVMI and NPs were consistent with the 2019 HFA minor criteria $[1,5]$. Thus, the 2016 ESC definition should have the advantage of higher sensitivity, and might be used for screening patients with symptoms suggestive of HF. The initial diagnostic work-up of a patient with suspected HF (including the cut-off points for NPs) proposed in the 2016 ESC HF guidelines was largely incorporated into step 1 (P) of the 2019 HFA-PEFF algorithm $[1,5]$.

A comparison of HFpEF diagnostic criteria from different documents is shown in Table 4.

\section{Are the 2019 HFA-PEFF score and the 2016 ASE/EACVI algorithm compatible?}

The 2016 ASE/EACVI algorithm refers to evaluation of $\mathrm{LV}$ diastolic function and relies purely on echocardiographic criteria [4]. On the contrary, the 2019 HFA-PEFF score was designed to diagnose $\mathrm{HFpEF}$ in symptomatic patients and requires both echocardiographic assessment and measurement of NPs [5]. As presented in Table 5, cut-off points for e' and the E/e' ratio in the two algorithms 
Table 4. Comparison of types of criteria used to diagnose heart failure with preserved ejection fraction (HFpEF) according to different recommendations.

\begin{tabular}{lcccc}
\hline Criteria & \multicolumn{4}{c}{ HFpEF/diastolic dysfunction definition } \\
\cline { 2 - 5 } & $\begin{array}{c}\text { 2016 ESC } \\
\text { guidelines }\end{array}$ & $\begin{array}{c}\text { 2016 ASE/EACVI } \\
\text { recommendations }\end{array}$ & $\begin{array}{c}2018 \text { H}_{2} \text { FPEF } \\
\text { score }\end{array}$ & $\begin{array}{c}\text { 2019 HFA-PEFF } \\
\text { score }\end{array}$ \\
\hline Clinical & $X$ & $X$ & $X$ & X \\
Echocardiographic & $X$ & $X$ & $X$ & $X$ \\
Natriuretic peptides & $X$ & & & $*$ \\
\hline
\end{tabular}

*The score is designed to diagnose HFpEF in stable, symptomatic patients. ASE - American Society of Echocardiography; EACVI - European Association of Cardiovascular Imaging; ESC — European Society of Cardiology; HFA — Heart Failure Association

Table 5. Cut-off points for tissue Doppler imaging-derived parameters and tricuspid regurgitation velocity (TRV) in different recommendations on the diagnosis of diastolic dysfunction.

\begin{tabular}{|c|c|c|c|}
\hline \multirow[t]{2}{*}{ Parameter } & \multicolumn{3}{|c|}{ HFpEF/diastolic dysfunction definition } \\
\hline & $\begin{array}{l}2016 \text { ESC } \\
\text { guidelines }\end{array}$ & $\begin{array}{l}2016 \text { ASE/EACVI } \\
\text { recommendations }\end{array}$ & $\begin{array}{l}2019 \text { HFA-PEFF } \\
\text { score }\end{array}$ \\
\hline Resting echocardiography & & & major criterion: \\
\hline $\mathrm{e}^{\prime}$ lateral $[\mathrm{cm} / \mathrm{s}]$ & $<10$ & $<10$ & $<10^{*}$ \\
\hline $\mathrm{e}^{\prime}$ septal $[\mathrm{cm} / \mathrm{s}]$ & $<8$ & $<7$ & $<7^{*}$ \\
\hline Average $\mathrm{E} / \mathrm{e}^{\prime}$ & $\geq 13$ & $>14$ & $\geq 15^{* *}$ \\
\hline $\mathrm{TRV}[\mathrm{m} / \mathrm{s}]$ & - & $>2.8$ & $>2.8$ \\
\hline \multicolumn{4}{|l|}{ Exercise echocardiography } \\
\hline Average $\mathrm{E} / \mathrm{e}^{\prime}$ & $>13$ & $>14^{* * *}$ & $\geq 15$ \\
\hline $\mathrm{TRV}[\mathrm{m} / \mathrm{s}]$ & - & $>2.8$ & $>3.4$ \\
\hline
\end{tabular}

*For patients < 75 years; **E/e' between 9 and 14 is a minor criterion; ***or septal E/e' > 15; ASE - American Society of Echocardiography; EACVI - European Association of Cardiovascular Imaging; ESC - European Society of Cardiology; HFA - Heart Failure Association; $\mathrm{HFpEF}$ - heart failure with preserved ejection fraction

are comparable $[4,5]$. However, given the different rules of point attribution, as well as obligatory NP measurement in the HFA-PEFF score, the two algorithms are not interchangeable, and some patients diagnosed with $\mathrm{HFpEF} /$ diastolic dysfunction according to one of them might not necessarily fulfil criteria allowing its unequivocal diagnosis according to the other (see examples, Fig. 4). Nonetheless, patients diagnosed with diastolic dysfunction using the ASE/EACVI algorithm will have at least intermediate probability of $\mathrm{HFpEF}$ in the HFA-PEFF score (because they will score at least two points). Conversely, patients with $\mathrm{HFpEF}$ diagnosis based on the HFA-PEFF score (5-6 points) might theoretically have normal diastolic function according to the ASE/EACVI algorithm, e.g. if they had significant LV hypertrophy with high NP concentrations (major criteria) with preserved e' velocities, low TRV, and LA that has not enlarged yet (E/e' ratio is expected to be elevated with high NPs, although this is not always the case, see
Fig. 4A). However, such a scenario seems less probable in clinical practice. Comparison of the diagnostic accuracy of the two algorithms, their mutual validation, and assessment of the proportion of reclassified cases should be the aims of future studies.

With a wider spectrum of echocardiographic parameters and NP measurement, the 2019 HFA-PEFF algorithm offers a more integrated approach to the diagnosis of $\mathrm{HFpEF}$, which may prove more reliable, although this still needs to be confirmed. On the other hand, apart from diagnosing diastolic dysfunction (including preclinical diastolic dysfunction), the $2016 \mathrm{ASE} / \mathrm{EACVI}$ criteria enable its grading with an estimation of LA pressure, which, although not very accurate, is very useful in clinical practice, especially for follow-up of HF patients and assessment of efficacy of diuretic treatment. Notably, this year, a modification of the 2016 ASE/ /EACVI algorithm was proposed by two of its authors, however, not as official recommendations [67]. 


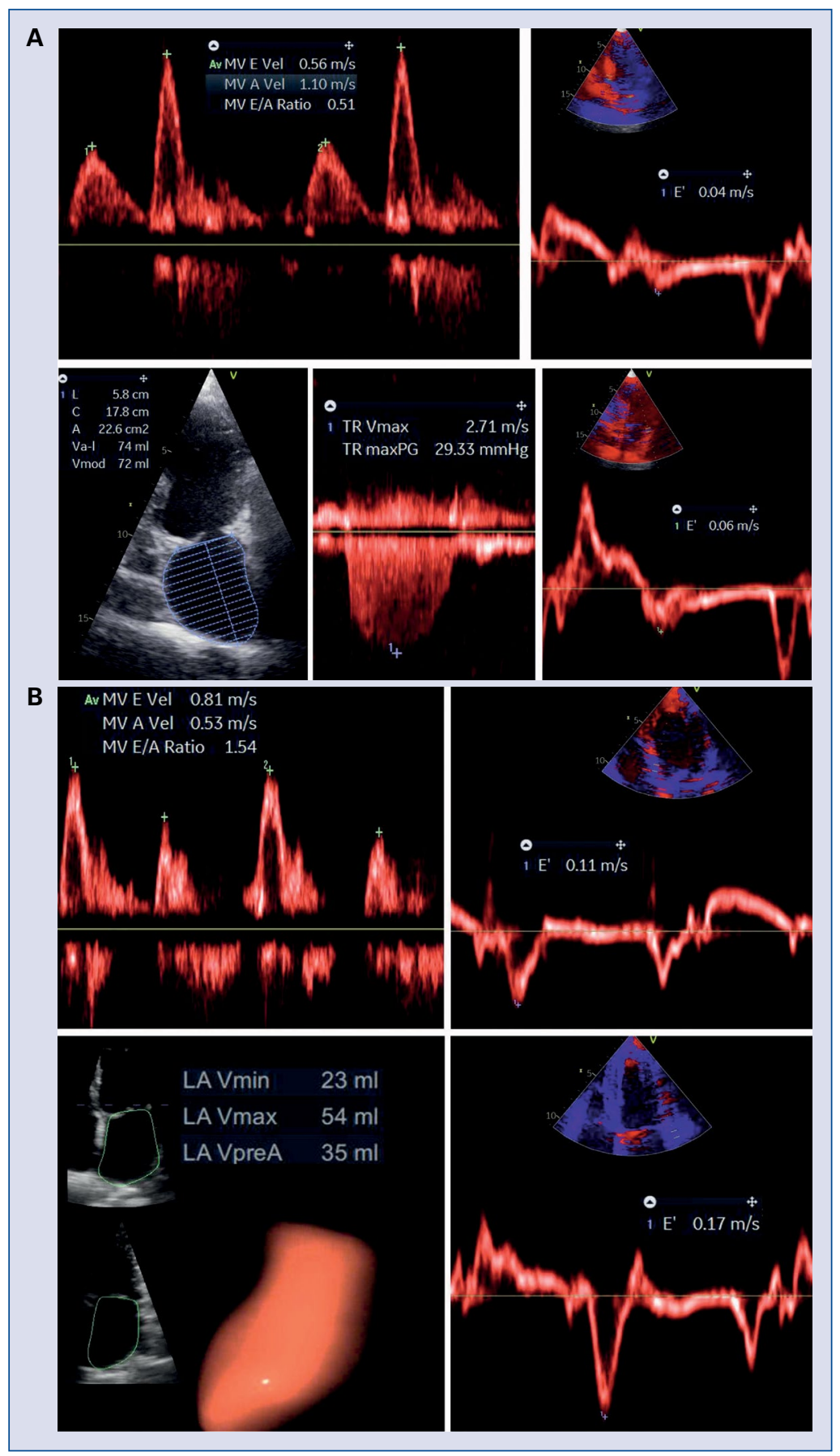

Figure 4. Comparison of the American Society of Echocardiography/European Association of Cardiovascular Imaging (ASE/EACVI) algorithm and the HFA-PEFF score based on clinical cases. A. An 88-year-old man with exertional dyspnea, sinus rhythm, and CCS with a history of percutaneous coronary intervention. Resting echocardiography revealed EF of 51\%, LVH (LVMI $125 \mathrm{~g} / \mathrm{m}^{2}$, RWT 0.48), reduced e' velocities with E/e' of 11, LAVI of $40 \mathrm{~mL} / \mathrm{m}^{2}$, and TRV of $2.71 \mathrm{~m} / \mathrm{s}$. NT-proBNP was $371 \mathrm{pg} / \mathrm{mL}$. Based on the ASE/EACVI algorithm, echocardiography was inconclusive for the diagnosis of diastolic dysfunction (two of four criteria positive). Given E velocity of $0.5 \mathrm{~m} / \mathrm{s}$, estimated resting LA pressure can be classified as normal; therefore, symptoms could either be attributable to CCS or would require assessment with diastolic stress test (see Fig. 2B). However, according to the HFA-PEFF score (a total of six points), the patient can be diagnosed with HFpEF without proceeding to stress test. B. A 51-year-old woman with sinus rhythm and exercise intolerance. Resting echocardiography revealed EF of $65 \%$, concentric LV remodeling (LVMI $69 \mathrm{~g} / \mathrm{m}^{2}$, RWT 0.49), normal e' velocities with $E / \mathrm{e}^{\prime}$ of 6 , and LAVI of $33 \mathrm{~mL} / \mathrm{m}^{2}$ (LA volume of $54 \mathrm{~mL}, B S A$ of $1.64 \mathrm{~m}^{2}$ ). There was no detectable TR Doppler signal profile. NT-proBNP was $338 \mathrm{pg} / \mathrm{mL}$. Based on the ASE/EACVI algorithm, the patient was classified as having normal diastolic function. However, according to the HFA-PEFF score, with a total of three points (two points for the biomarker domain and one point for the morphological domain), HFpEF probability is intermediate, and the patient requires diastolic stress test. 


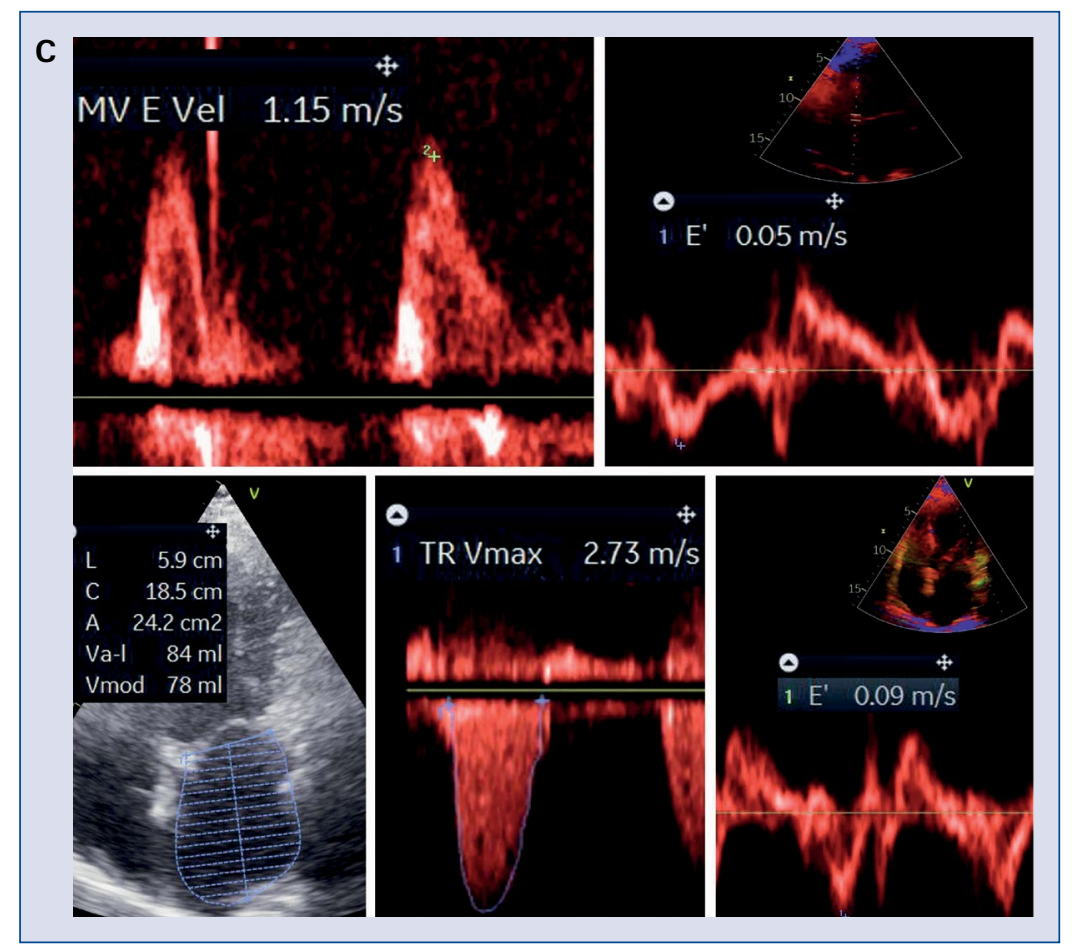

Figure 4 (cont.). C. A 75-year-old woman with atrial fibrillation. Resting echocardiography revealed EF of 57\%, concentric LVH (LVMI $111 \mathrm{~g} / \mathrm{m}^{2}$, RWT 0.58), and e' septal and lateral of 5 and $9 \mathrm{~cm} / \mathrm{s}$, respectively (reduced as per ASE/ /EACVI algorithm, but within the norm range for age as per HFA-PEFF score), with E/e' of $16.4, \mathrm{LAVI}$ of $42 \mathrm{~mL} / \mathrm{m}^{2}$, and moderate TR with TRV of $2.73 \mathrm{~m} / \mathrm{s}$. NT-proBNP was $849 \mathrm{pg} / \mathrm{mL}$. According to the ASE/EACVI algorithm, the patient has diastolic dysfunction. This is consistent with the result of the HFA-PEFF score (six points, diagnosis of HFpEF); BSA - body surface area; CCS — chronic coronary syndrome; EF — ejection fraction; HFpEF — heart failure with preserved ejection fraction; LA - left atrium; LAVI — left atrial volume index; LV — left ventricle; LVH — left ventricular hypertrophy; LVMI - left ventricular mass index; NT-proBNP - N-terminal pro-B-type natriuretic peptide; RWT — relative wall thickness; TRV — tricuspid regurgitation velocity.

\section{Do the European HFA-PEFF score and the American $\mathrm{H}_{2}$ FPEF score refer to the same patients?}

The two definitions share similarities: both use a combination of various parameters in the form of a scoring system, and both are based on a Bayesian approach, describing HFpEF likelihood rather than providing a straightforward diagnosis. Both are meant for evaluation of chronic, symptomatic patients (the $\mathrm{H}_{2} \mathrm{FPEF}$ score - those with unexplained dyspnea). However, there are some major differences between the two scores. First, the $\mathrm{H}_{2} \mathrm{FPEF}$ score is an evidence-based tool derived and validated in patients referred for RHC, while the HFA-PEFF score is an expert consensus-based concept. Second, the $\mathrm{H}_{2} \mathrm{FPEF}$ score is predominantly based on clinical profiles, while the idea behind the HFA-PEFF score is that hemodynamic abnormalities in HFpEF can and should be objectivized by echocardiography and NPs $[5,54]$. Thus, the $\mathrm{H}_{2} \mathrm{FPEF}$ score could make a convenient bedside screening tool incorporated as step $1(\mathrm{P})$ into the HFA-PEFF algorithm. Another premise for the use of the $\mathrm{H}_{2} \mathrm{FPEF}$ score as a screening method is its high sensitivity, resulting from the fact that almost half of the HFpEF patients in the derivation cohort had early-stage HFpEF with elevation of LV filling pressures only during exertion [54, 57]. Third, the effect of AF on the probability of $\mathrm{HFpEF}$ seems discordant in the two scores: in the $\mathrm{H}_{2} \mathrm{FPEF}$ score the presence of $\mathrm{AF}$ significantly increases the likelihood of HFpEF, while in the HFA-PEFF score it necessitates higher cut-off points of NPs and LAVI, decreasing the probability of HFpEF diagnosis at lower values. Thus, the same patient might even be classified at the opposing ends of the spectrum of HFpEF probability by each of the two scores. An elderly patient with unexplained dyspnea, AF, and a BMI of $>30 \mathrm{~kg} / \mathrm{m}^{2}$ would be attributed a total of six points in the $\mathrm{H}_{2} \mathrm{FPEF}$ score, satisfying the criteria for $\mathrm{HFpEF}$, regardless of the echocardiographic result (and regardless of NP measurement, which is not required in this score) [54]. In the HFA-PEFF algorithm, such a patient would only complete step $1(\mathrm{P})$ and would require 
a thorough echocardiographic and NP assessment using the HFA-PEFF score (step $2[\mathrm{E}]$ ), with higher cut-offs for NPs and LAVI due to AF [5].

A comparison of the two scores in an Asian population demonstrated high specificities of both scores $(81 \%$ for the HFA-PEFF score and $88 \%$ for the $\mathrm{H}_{2} \mathrm{FPEF}$ score) with significantly higher sensitivity of the HFA-PEFF score (74\%) than of the $\mathrm{H}_{2}$ FPEF score (25\%) [68]. This surprisingly low sensitivity of the $\mathrm{H}_{2} \mathrm{FPEF}$ score might be explained by the fact that Asian HFpEF patients are almost a decade younger and have a lower prevalence of obesity and AF (two and three points in the $\mathrm{H}_{2}$ FPEF score, respectively) than their western counterparts [69]. Thus, predictive values of different scores may substantially vary depending on the population studied.

\section{Practical considerations on clinical profiles}

Analysis of the presented HFpEF definitions may lead to a few realizations regarding clinical characteristics, including female sex, obesity, and AF.

Heart failure with preserved EF is widely regarded as a disease of older women [70]. However, even though the proportion of women is higher than men in the HFpEF population (contrary to $\mathrm{HFrEF}$ ), the incidence of HFpEF adjusted for age and other risk factors tends to be similar in women and men [16, 71-73]. Notably, female sex was not included as a criterion in any of the above presented scores or definitions [1-11, 54]. A higher proportion of women among $\mathrm{HFpEF}$ patients might result from their higher life expectancy [72]. However, estrogen deficiency has been postulated as one of the contributors underlying $\mathrm{HFpEF}$ development in post-menopausal women [74-76]. Among HFpEF patients, women have smaller LV dimensions with poorer diastolic reserve and higher LV filling pressures at rest and exercise [77].

Obesity should not be perceived as a sufficient explanation for breathlessness or low exercise capacity but as a strong risk factor of $\mathrm{HFpEF}$ $[70,71]$. This is reflected by two points attributed for a BMI of $>30 \mathrm{~kg} / \mathrm{m}^{2}$ in the $\mathrm{H}_{2} \mathrm{FPEF}$ score [54]. Importantly, obesity can lead to NP concentrations that are normal or close to normal, even in the presence of HFpEF $[1,36,38]$. Unfortunately, this was not accounted for in the HFA-PEFF score [5]. Based on observations from hemodynamic studies, the existence of a distinct, obese phenotype of HFpEF has been postulated recently $[78,79]$.
Atrial fibrillation is highly prevalent in $\mathrm{HFpEF}$ - even more prevalent than in HFrEF $[16,80$, 81]. This is because AF is not only a consequence of elevation of LA pressure and LA enlargement in the course of $\mathrm{HF}$ (regardless of $\mathrm{EF}$ ), but also because $\mathrm{AF}$ and $\mathrm{HFpEF}$ share a common pathophysiological background and risk factors (older age, obesity, hypertension, diabetes) [82, 83]. However, AF can also be regarded as an important confounder in diagnosing HFpEF; first, because it can lead to an increase in NPs and LAVI even in the absence of HFpEF, and second, because it hinders echocardiographic evaluation of diastolic function [5]. Thus, as mentioned above, different scores represent different approaches to AF: the more "clinical" $\mathrm{H}_{2} \mathrm{FPEF}$ score recognizes it as a risk factor, while the HFA-PEFF score sees it as a confounding factor $[5,54]$.

Last but not least, even modern HFpEF definitions are, to some extent, "diagnoses of exclusion". For example, the derivation cohort for the $\mathrm{H}_{2} \mathrm{FPEF}$ score included patients referred for RHC for "unexplained" dyspnea, i.e. after exclusion of HFrEF, valvular heart disease, pulmonary arterial hypertension, constrictive pericarditis, clinically relevant pulmonary disease, and other conditions that might have accounted for their symptoms [54]. Similarly, step 1 (P) of the HFA-PEFF algorithm assumes exclusion of other cardiac and non-cardiac causes of dyspnea [5]. This is understandable given the aforementioned low specificity of most currently available echocardiographic and biochemical parameters. Still, in the elderly, multimorbidity is highly prevalent, and even more so in patients with HFpEF [70-72]. A single patient may, and often does, have several comorbidities, apart from $\mathrm{HFpEF}$, that might add to his/her symptoms, and all of them deserve recognition and treatment. Thus, validation of the presented $\mathrm{HFpEF}$ definitions should ideally be conducted in unselected cohorts of symptomatic patients.

\section{HFpEF definitions in clinical trials}

Table 6 presents inclusion criteria applied in major HFpEF randomized clinical trials, which are largely inconsistent with the definitions reviewed above. Those trials included also a subset of patients that we nowadays refer to as $\mathrm{HF}$ with mid-range EF [6-11]. Analyzing inclusion criteria in those studies, over the years, an evolution of HFpEF definition can be seen, from more clinically based to objectivized by echocardiography and NPs. 
Table 6. Inclusion criteria in some major heart failure with preserved ejection fraction (HFpEF) trials.

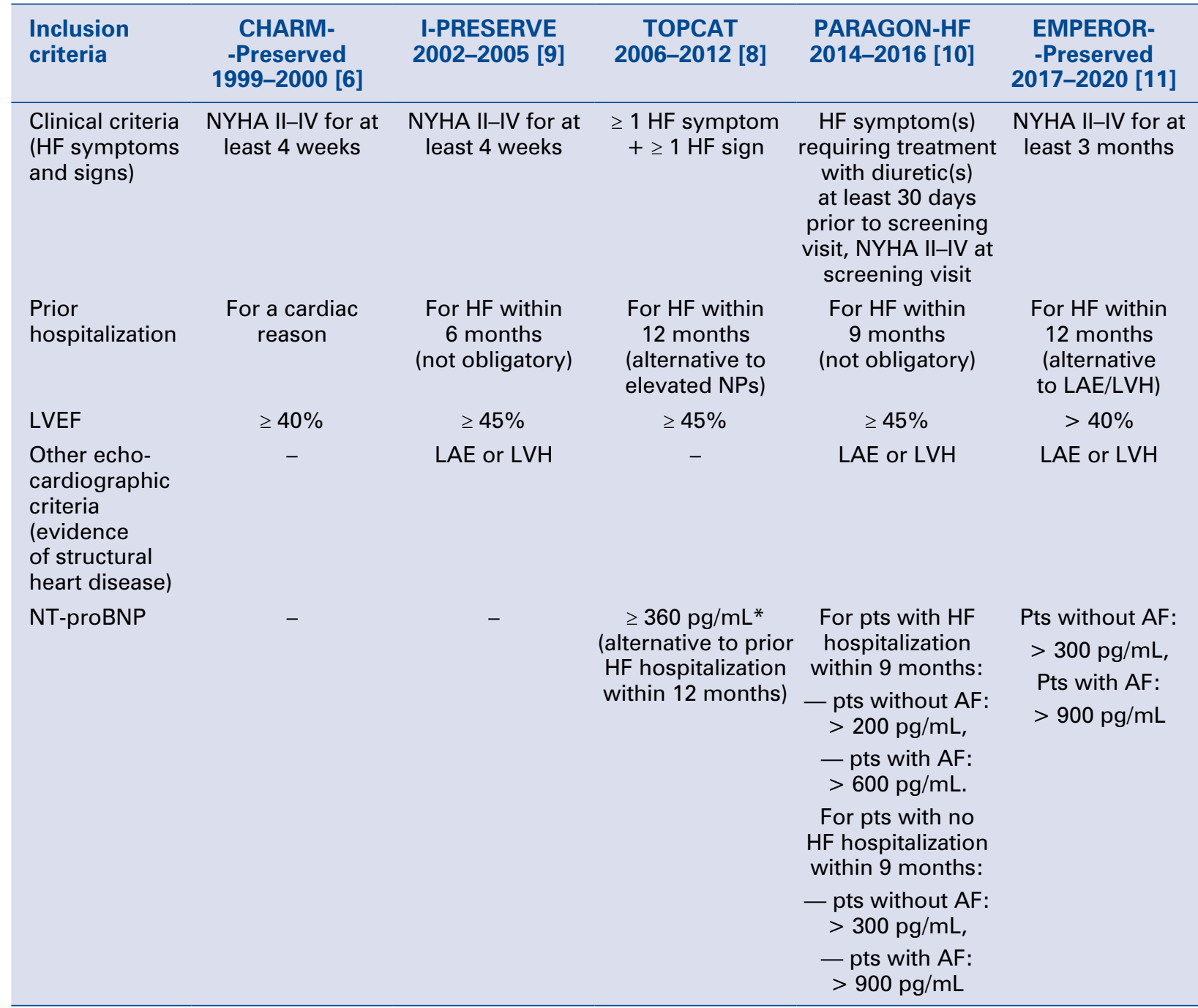

*or BNP $\geq 100 \mathrm{pg} / \mathrm{mL}$. AF — atrial fibrillation; BNP - B-type natriuretic peptide; CHARM Preserved - Candesartan Cilexetil in Heart Failure Assessment of Reduction in Mortality and Morbidity; EMPEROR-Preserved - Empagliflozin Outcome Trial in Patients With Chronic Heart Failure With Preserved Ejection Fraction; HF — heart failure; I-PRESERVE — Irbesartan in Heart Failure and Preserved Ejection Fraction; LAE - left atrial enlargement; LVEF — left ventricular ejection fraction; LVH - left ventricular hypertrophy; NPs — natriuretic peptides; NT-proBNP — N-terminal pro-BNP; NYHA — New York Heart Association; PARAGON-HF — Prospective Comparison of ARNI with ARB Global Outcomes in HF With Preserved Ejection Fraction; pts - patients; TOPCAT — Treatment of Preserved Cardiac Function Heart Failure with an Aldosterone Antagonist

Interestingly, prior HF hospitalization was (and still is) a common (although not always obligatory) criterion for inclusion, driven by the intent to recruit higher risk patients with more potential to prove benefits from treatment by event reduction. This approach also reflects the fact that HFpEF manifestation is more evident in the acute setting of symptom exacerbation, but on the other hand might have led to its overdiagnosis and loss of the effect of spironolactone on the primary endpoint in the TOPCAT (Treatment of Preserved Cardiac Function Heart Failure with an Aldosterone Antagonist) trial $[8,84]$. For now, no treatment tested in clinical trials has demonstrated an improvement in survival in HFpEF, although some benefit was observed when analyzing other clinical endpoints (e.g. HF hospitalizations for candesartan, perindopril, and spironolactone) or specific HFpEF subpopulations (e.g. women for sacubitril-valsartan) [6, 8, 10, 85]. Similar to HFrEF, HFpEF is not a homogenous clinical entity, but encompasses a wide spectrum of underlying diseases ultimately leading to elevated LA pressure despite preserved EF. This heterogeneity of the HFpEF syndrome may, at least in part, account for disappointing results of clinical HFpEF trials [86]. It is postulated that the "one fits all" strategy may need to be changed to a more individualized approach based on phenotypic patient characterization including cardiac and non-cardiac comorbidities [87-91]. 


\section{Conclusions: Which definition shoud we use?}

The abundance of diagnostic criteria for $\mathrm{HFpEF}$ results from uncertainty regarding its underlying pathophysiology and lack of definition-guided treatment [1-11, 13, 54, 92]. At present, the 2019 HFA-PEFF algorithm constitutes the most comprehensive HFpEF definition, and its widespread use should be supported [5]. However, the 2016 ESC guidelines on HF can still be used in step 1 (pretest assessment) of the HFA-PEFF algorithm [1]. Alternatively, implementation of the $\mathrm{H}_{2} \mathrm{FPEF}$ score in step $1(\mathrm{P})$ might be advocated in patients with unexplained dyspnea, especially if NP measurements are not readily available [54]. Thus, in patients with suspected HFpEF, we suggest using the $2016 \mathrm{ESC} \mathrm{HFpEF}$ definition or estimation of $\mathrm{HFpEF}$ probability with the $\mathrm{H}_{2} \mathrm{FPEF}$ score for screening purposes by general practitioners, internists, geriatricians, or general cardiologists (as step $1[\mathrm{P}]$ ), and if positive, verification of diagnosis using step 2 ([E]; the HFA-PEFF score) and, when indicated, step $3\left(\mathrm{~F}_{1}\right)$ of the HFA-PEFF algorithm by an $\mathrm{HF}$ specialist.

The 2016 ASE/EACVI definition was less comprehensive than the new HFA-PEFF algorithm but had an important practical advantage: it enabled echocardiographers to establish or exclude the presence of diastolic dysfunction, grade it, and summarize their conclusions in an echocardiographic report (simply the presence or absence of diastolic dysfunction at rest) [4]. This facilitated confirmation or exclusion of HFpEF diagnosis for clinicians who might not be familiarized with detailed echocardiographic indices of diastolic function. In the 2019 HFA-PEFF score, echocardiographic parameters and NP concentrations are analyzed in conjunction, which potentially leads to some confusion among non-HF specialists, hindering everyday use of the score due to its complexity [5]. Thus, in patients evaluated for dyspnea, it might be reasonable for echocardiographers to summarize the results from the two echocardiographic domains (functional and morphological) of the HFA-PEFF score by providing the total number of points ( $0-4$ out of 4 possible) in conclusions of an echocardiographic report. The attending physician could then simply add $0-2$ points depending on NP concentration to obtain the final result of the HFA-PEFF score.

Studies validating the HFA-PEFF score against invasive measurements, with comparison to the ASE/EACVI algorithm and the $\mathrm{H}_{2} \mathrm{FPEF}$ score, are warranted. The future will show whether this HFpEF definition will hold or whether it will be replaced by new diagnostic criteria - maybe originating from a positive randomized clinical trial?

\section{Acknowledgements}

This article is an official publication of "Club 30" of the Polish Cardiac Society

\section{Conflict of interest: None declared}

\section{References}

1. Ponikowski P, Voors A, Anker S, et al. 2016 ESC Guidelines for the diagnosis and treatment of acute and chronic heart failure. Eur Heart J. 2016; 37(27): 2129-2200, doi: 10.1093/eurheartj/ehw128.

2. Lindenfeld J, Albert NM, Boehmer JP, et al. Heart Failure Society of America. HFSA 2010 Comprehensive Heart Failure Practice Guideline. J Card Fail. 2010; 16(6): e1-e194, doi: 10.1016/j.cardfail.2010.04.004, indexed in Pubmed: 20610207.

3. Yancy C, Jessup M, Bozkurt B, et al. 2013 ACCF/AHA guideline for the management of heart failure: a report of the American College of Cardiology Foundation/American Heart Association Task Force on practice guidelines. Circulation. 2013; 128(16), doi: 10.1161/cir.0b013e31829e8776.

4. Nagueh SF, Smiseth OA, Appleton CP, et al. Recommendations for the Evaluation of Left Ventricular Diastolic Function by Echocardiography: An Update from the American Society of Echocardiography and the European Association of Cardiovascular Imaging. J Am Soc Echocardiogr. 2016; 29(4): 277-314, doi: 10.1016/j. echo.2016.01.011, indexed in Pubmed: 27037982.

5. Pieske B, Tschöpe C, de Boer RA, et al. How to diagnose heart failure with preserved ejection fraction: the HFA-PEFF diagnostic algorithm: a consensus recommendation from the Heart Failure Association (HFA) of the European Society of Cardiology (ESC). Eur Heart J. 2019; 40(40): 3297-3317, doi: 10.1093/eurheartj/ehz641, indexed in Pubmed: 31504452.

6. Yusuf S, Pfeffer MA, Swedberg K, et al. CHARM Investigators and Committees. Effects of candesartan in patients with chronic heart failure and preserved left-ventricular ejection fraction: the CHARM-Preserved Trial. Lancet. 2003; 362(9386): 777-781, doi: 10.1016/S0140-6736(03)14285-7, indexed in Pubmed: 13678871.

7. Redfield MM, Chen HH, Borlaug BA, et al. RELAX Trial. Effect of phosphodiesterase- 5 inhibition on exercise capacity and clinical status in heart failure with preserved ejection fraction: a randomized clinical trial. JAMA. 2013; 309(12): 1268-1277, doi: 10.1001/jama.2013.2024, indexed in Pubmed: 23478662.

8. Pitt B, Pfeffer M, Assmann S, et al. Spironolactone for Heart Failure with Preserved Ejection Fraction. N Engl J Med. 2014; 370(15): 1383-1392, doi: 10.1056/nejmoa1313731.

9. Carson P, Anand I, Win S, et al. The hospitalization burden and post-hospitalization mortality risk in heart failure with preserved ejection fraction. JACC: Heart Failure. 2015; 3(6): 429-441, doi: 10.1016/j.jchf.2014.12.017.

10. Solomon SD, McMurray JJV, Anand IS, et al. PARAGON-HF Investigators and Committees. Angiotensin-Neprilysin Inhibition in Heart Failure with Preserved Ejection Fraction. N Engl J Med. 2019; 381(17): 1609-1620, doi: 10.1056/NEJMoa1908655, indexed in Pubmed: 31475794.

11. Anker SD, Butler J, Filippatos GS, et al. Evaluation of the effects of sodium-glucose co-transporter 2 inhibition with empagliflozin 
on morbidity and mortality in patients with chronic heart failure and a preserved ejection fraction: rationale for and design of the EMPEROR-Preserved Trial. Eur J Heart Fail. 2019; 21(10): 1279-1287.

12. Senni M, Caravita S, Paulus WJ. Do existing definitions identify subgroup phenotypes or reflect the natural history of heart failure with preserved ejection fraction? Circulation. 2019; 140(5): 366-369, doi: 10.1161/CIRCULATIONAHA.119.041657, indexed in Pubmed: 31356132.

13. Lam CSP, Voors AA, de Boer RA, et al. Heart failure with preserved ejection fraction: from mechanisms to therapies. Eur Heart J. 2018; 39(30): 2780-2792, doi: 10.1093/eurheartj/ehy301, indexed in Pubmed: 29905796.

14. Carey SA, Bass K, Saracino G, et al. Probability of Accurate Heart Failure Diagnosis and the Implications for Hospital Readmissions. Am J Cardiol. 2017; 119(7): 1041-1046, doi: 10.1016/j. amjcard.2016.12.010, indexed in Pubmed: 28132683.

15. Hage C, Löfström U, Donal E, et al. Do patients with acute heart failure and preserved ejection fraction have heart failure at follow-up: implications of the framingham criteria. J Card Fail. 2020; 26(8): 673-684, doi: 10.1016/j.cardfail.2019.04.013, indexed in Pubmed: 31035008.

16. Kapłon-Cieślicka A, Tymińska A, Peller M, et al. Diagnosis, clinical course, and 1-year outcome in patients hospitalized for heart failure with preserved ejection fraction (from the Polish cohort of the European Society of Cardiology Heart Failure Long-Term Registry). Am J Cardiol. 2016; 118(4): 535-542, doi: 10.1016/j. amjcard.2016.05.046, indexed in Pubmed: 27374606.

17. Kapłon-Cieślicka A, Laroche C, Crespo-Leiro MG, et al. Is heart failure misdiagnosed in hospitalized patients with preserved ejection fraction? From the European Society of Cardiology - Heart Failure Association EURObservational Research Programme Heart Failure Long-Term Registry. ESC Heart Fail. 2020; 7(5): 2098-2112, doi: 10.1002/ehf2.12817, indexed in Pubmed: 32618139.

18. Verdú-Rotellar JM, Frigola-Capell E, Alvarez-Pérez R, et al. Validation of heart failure diagnosis registered in primary care records in two primary care centres in Barcelona (Spain) and factors related. A cross-sectional study. Eur J Gen Pract. 2017; 23(1): 107-113, doi: 10.1080/13814788.2017.1305104, indexed in Pubmed: 28376668.

19. Delekta J, Hansen SM, AlZuhairi KS, et al. The validity of the diagnosis of heart failure (I50.0-I50.9) in the Danish National Patient Register. Dan Med J. 2018; 65(4): pii: A5470.

20. Ho JE, Zern EK, Wooster L, et al. Differential clinical profiles, exercise responses, and outcomes associated with existing HFpEF definitions. Circulation. 2019; 140(5): 353-365, doi: 10.1161/CIRCULATIONAHA.118.039136, indexed in Pubmed: 31132875.

21. Balaney B, Medvedofsky D, Mediratta A, et al. Invasive Validation of the Echocardiographic Assessment of Left Ventricular Filling Pressures Using the 2016 Diastolic Guidelines: Head-to-Head Comparison with the 2009 Guidelines. J Am Soc Echocardiogr. 2018; 31(1): 79-88, doi: 10.1016/j.echo.2017.09.002, indexed in Pubmed: 29111121.

22. Andersen OS, Smiseth OA, Dokainish H, et al. Estimating Left Ventricular Filling Pressure by Echocardiography. J Am Coll Cardiol. 2017; 69(15): 1937-1948, doi: 10.1016/j.jacc.2017.01.058, indexed in Pubmed: 28408024.

23. Lancellotti P, Galderisi M, Edvardsen T, et al. Echo-Doppler estimation of left ventricular filling pressure: results of the multicentre EACVI Euro-Filling study. Eur Heart J Cardiovasc Imag- ing. 2017; 18(9): 961-968, doi: 10.1093/ehjci/jex067, indexed in Pubmed: 28444160.

24. Obokata M, Kane GC, Reddy YNV, et al. Role of diastolic stress testing in the evaluation for heart failure with preserved ejection fraction: a simultaneous invasive-echocardiographic study. Circulation. 2017; 135(9): 825-838, doi: 10.1161/CIRCULATIONAHA.116.024822, indexed in Pubmed: 28039229.

25. Nauta JF, Hummel YM, van der Meer P, et al. Correlation with invasive left ventricular filling pressures and prognostic relevance of the echocardiographic diastolic parameters used in the 2016 ESC heart failure guidelines and in the 2016 ASE/EACVI recommendations: a systematic review in patients with heart failure with preserved ejection fraction. Eur J Heart Fail. 2018; 20(9): 1303-1311, doi: 10.1002/ejhf.1220, indexed in Pubmed: 29877602.

26. Sharifov OF, Schiros CG, Aban I, et al. Diagnostic accuracy of tissue doppler index E/e' for evaluating left ventricular filling pressure and diastolic dysfunction/heart failure with preserved ejection fraction: a systematic review and meta-analysis. J Am Heart Assoc. 2016; 5(1), doi: 10.1161/JAHA.115.002530, indexed in Pubmed: 26811160.

27. Matsushita K, Minamishima T, Goda A, et al. Comparison of the reliability of E/E' to estimate pulmonary capillary wedge pressure in heart failure patients with preserved ejection fraction versus those with reduced ejection fraction. Int J Cardiovasc Imaging. 2015; 31(8): 1497-1502, doi: 10.1007/s10554-015-0718-7, indexed in Pubmed: 26216649.

28. Obokata M, Borlaug BA. The strengths and limitations of E/e' in heart failure with preserved ejection fraction. Eur J Heart Fail. 2018; 20(9): 1312-1314, doi: 10.1002/ejhf.1250, indexed in Pubmed: 29932475.

29. Gao C, Tao Y, Pan J, et al. Evaluation of elevated left ventricular end diastolic pressure in patients with preserved ejection fraction using cardiac magnetic resonance. Eur Radiol. 2019; 29(5): 2360-2368, doi: 10.1007/s00330-018-5955-4, indexed in Pubmed: 30631923.

30. Sharifov OF, Gupta H. What is the evidence that the tissue Doppler index E/e' reflects left ventricular filling pressure changes after exercise or pharmacological intervention for evaluating diastolic function? A systematic review. J Am Heart Assoc. 2017; 6(3), doi: 10.1161/JAHA.116.004766, indexed in Pubmed: 28298372 .

31. Smiseth OA. Evaluation of left ventricular diastolic function: state of the art after 35 years with Doppler assessment. J Echocardiogr. 2018; 16(2): 55-64, doi: 10.1007/s12574-0170364-2, indexed in Pubmed: 29236226.

32. Opdahl A, Remme EW, Helle-Valle T, et al. Determinants of left ventricular early-diastolic lengthening velocity: independent contributions from left ventricular relaxation, restoring forces, and lengthening load. Circulation. 2009; 119(19): 2578-2586, doi: 10.1161/CIRCULATIONAHA.108.791681, indexed in Pubmed: 19414640.

33. Graham RJ, Gelman JS, Donelan L, et al. Effect of preload reduction by haemodialysis on new indices of diastolic function. Clin Sci (Lond). 2003; 105(4): 499-506, doi: 10.1042/CS20030059, indexed in Pubmed: 12816536.

34. D'Andrea A, Vriz O, Ferrara F, et al. Reference ranges and physiologic variations of left E/e' ratio in healthy adults: clinical and echocardiographic correlates. J Cardiovasc Echogr. 2018; 28(2): 101-108, doi: 10.4103/jcecho.jcecho_57_17, indexed in Pubmed: 29911006. 
35. Harada E, Mizuno Y, Kugimiya F, et al. Sex differences in heart failure with preserved ejection fraction reflected by B-type natriuretic peptide level. Am J Med Sci. 2018; 356(4): 335-343, doi: 10.1016/j.amjms.2018.06.009, indexed in Pubmed: 30360801.

36. Anjan VY, Loftus TM, Burke MA, et al. Prevalence, clinical phenotype, and outcomes associated with normal B-type natriuretic peptide levels in heart failure with preserved ejection fraction. Am J Cardiol. 2012; 110(6): 870-876, doi: 10.1016/j.amjcard.2012.05.014, indexed in Pubmed: 22681864.

37. Maisel A, Mueller C, Adams K, et al. State of the art: using natriuretic peptide levels in clinical practice. Eur J Heart Fail. 2008; 10(9): 824-839, doi: 10.1016/j.ejheart.2008.07.014, indexed in Pubmed: 18760965.

38. Meijers WC, Hoekstra T, Jaarsma T, et al. Patients with heart failure with preserved ejection fraction and low levels of natriuretic peptides. Neth Heart J. 2016; 24(4): 287-295, doi: 10.1007/ s12471-016-0816-8, indexed in Pubmed: 26940695.

39. Borlaug B, Nishimura R, Sorajja P, et al. Exercise hemodynamics enhance diagnosis of early heart failure with preserved ejection fraction. Circulation: Heart Failure. 2010; 3(5): 588-595, doi: 10.1161/circheartfailure.109.930701.

40. Zaphiriou A, Robb S, Murray-Thomas T, et al. The diagnostic accuracy of plasma BNP and NTproBNP in patients referred from primary care with suspected heart failure: results of the UK natriuretic peptide study. Eur J Heart Fail. 2005; 7(4): 537541, doi: 10.1016/j.ejheart.2005.01.022, indexed in Pubmed: 15921792.

41. Barberato SH, Mantilla DEV, Misocami MA, et al. Effect of preload reduction by hemodialysis on left atrial volume and echocardiographic Doppler parameters in patients with end-stage renal disease. Am J Cardiol. 2004; 94(9): 1208-1210, doi: 10.1016/j. amjcard.2004.07.100, indexed in Pubmed: 15518627.

42. Fijalkowski M, Koprowski A, Gruchala M, et al. Effect of preload reduction by hemodialysis on myocardial ultrasonic characterization, left atrial volume, and Doppler tissue imaging in patients with end-stage renal disease. J Am Soc Echocardiogr. 2006; 19(11): 1359-1364, doi: 10.1016/j.echo.2006.05.020, indexed in Pubmed: 17098139.

43. Lam CSP, Borlaug BA, Kane GC, et al. Age-associated increases in pulmonary artery systolic pressure in the general population. Circulation. 2009; 119(20): 2663-2670, doi: 10.1161/CIRCULATIONAHA.108.838698, indexed in Pubmed: 19433755.

44. D'Alto M, Romeo E, Argiento P, et al. Accuracy and precision of echocardiography versus right heart catheterization for the assessment of pulmonary hypertension. Int J Cardiol. 2013; 168(4): 4058-4062, doi: 10.1016/j.jijcard.2013.07.005, indexed in Pubmed: 23890907.

45. Fisher MR, Forfia PR, Chamera E, et al. Accuracy of Doppler echocardiography in the hemodynamic assessment of pulmonary hypertension. Am J Respir Crit Care Med. 2009; 179(7): 615-621, doi: 10.1164/rccm.200811-16910C, indexed in Pubmed: 19164700 .

46. Galiè N, Humbert M, Vachiery JL, et al. 2015 ESC/ERS Guidelines for the diagnosis and treatment of pulmonary hypertension. Eur Respir J. 2015; 46(4): 903-975, doi: 10.1183/13993003.01032-2015.

47. Kjaergaard J, Snyder EM, Hassager C, et al. Impact of preload and afterload on global and regional right ventricular function and pressure: a quantitative echocardiography study. J Am Soc Echocardiogr. 2006; 19(5): 515-521, doi: 10.1016/j. echo.2005.12.021, indexed in Pubmed: 16644434.

48. Paulus WJ, van Ballegoij JJM. Treatment of heart failure with normal ejection fraction: an inconvenient truth! J Am Coll Cardiol.
2010; 55(6): 526-537, doi: 10.1016/j.jacc.2009.06.067, indexed in Pubmed: 20152557.

49. Kovacs G, Herve P, Barbera JA, et al. An official European Respiratory Society statement: pulmonary haemodynamics during exercise. Eur Respir J. 2017; 50(5), doi: 10.1183/13993003.005782017, indexed in Pubmed: 29167297.

50. Forfia PR, Watkins SP, Rame JE, et al. Relationship between B-type natriuretic peptides and pulmonary capillary wedge pressure in the intensive care unit. J Am Coll Cardiol. 2005; 45(10): 1667-1671, doi: 10.1016/j.jacc.2005.01.046, indexed in Pubmed: 15893185.

51. Chetrit M, Cremer PC, Klein AL. Imaging of diastolic dysfunction in community-based epidemiological studies and randomized controlled trials of HFpEF. JACC Cardiovasc Imaging. 2020; 13(1 Pt 2): 310-326, doi: 10.1016/j.jcmg.2019.10.022, indexed in Pubmed: 31918900.

52. Pinedo M, Villacorta E, Tapia C, et al. Inter- and intra-observer variability in the echocardiographic evaluation of right ventricular function. Rev Esp Cardiol. 2010; 63(7): 802-809, doi: 10.1016/ s1885-5857(10)70165-1, indexed in Pubmed: 20609314.

53. Olmos-Temois SG, Santos-Martínez LE, Álvarez-Álvarez R, et al. Interobserver agreement on the echocardiographic parameters that estimate right ventricular systolic function in the early postoperative period of cardiac surgery. Med Intensiva. 2016; 40(8): 491-498, doi: 10.1016/j.medin.2016.02.013, indexed in Pubmed: 27198648.

54. Reddy YNV, Carter RE, Obokata M, et al. A simple, evidencebased approach to help guide diagnosis of heart failure with preserved ejection fraction. Circulation. 2018; 138(9): 861-870, doi: 10.1161/CIRCULATIONAHA.118.034646, indexed in Pubmed: 29792299 .

55. Li S, Churchill T, Curreri L, et al. Diagnosing HFpEF: validation of a noninvasive diagnostic approach against invasive hemodynamics. J Am Coll Cardiol. 2020; 75(11): 911, doi: 10.1016/ s0735-1097(20)31538-2.

56. Nagueh S, Appleton C, Gillebert T, et al. Recommendations for the evaluation of left ventricular diastolic function by echocardiography. J Am Soc Echocardiogr. 2009; 22(2): 107-133, doi: 10.1016/j.echo.2008.11.023.

57. Sepehrvand N, Alemayehu W, Dyck GJB, et al. External validation of the HF-PEF model in diagnosing patients with heart failure and preserved ejection fraction. Circulation. 2019; 139(20): 2377-2379, doi: 10.1161/CIRCULATIONAHA.118.038594, indexed in Pubmed: 31082301.

58. Sueta D, Yamamoto E, Nishihara T, et al. H2FPEF score as a prognostic value in hfpef patients. Am J Hypertens. 2019; 32(11): 1082-1090, doi: 10.1093/ajh/hpz108, indexed in Pubmed: 31271191.

59. Suzuki S, Kaikita K, Yamamoto E, et al. H FPEF score for predicting future heart failure in stable outpatients with cardiovascular risk factors. ESC Heart Fail. 2020; 7(1): 65-74, doi: 10.1002/ ehf2.12570, indexed in Pubmed: 31967406.

60. Tao Y, Wang W, Zhu J, et al. HFPEF score predicts 1-year rehospitalisation of patients with heart failure with preserved ejection fraction. Postgrad Med J. 2020 [Epub ahead of print], doi: 10.1136/postgradmedj-2019-137434, indexed in Pubmed: 32114489.

61. Morris DA, Ma XX, Belyavskiy E, et al. Left ventricular longitudinal systolic function analysed by $2 \mathrm{D}$ speckle-tracking echocardiography in heart failure with preserved ejection fraction: a meta-analysis. Open Heart. 2017; 4(2): e000630, doi: 10.1136/ openhrt-2017-000630, indexed in Pubmed: 29018535. 
62. DeVore AD, McNulty S, Alenezi F, et al. Impaired left ventricular global longitudinal strain in patients with heart failure with preserved ejection fraction: insights from the RELAX trial. Eur J Heart Fail. 2017; 19(7): 893-900, doi: 10.1002/ejhf.754, indexed in Pubmed: 28194841.

63. Tschöpe C, Senni M. Usefulness and clinical relevance of left ventricular global longitudinal systolic strain in patients with heart failure with preserved ejection fraction. Heart Fail Rev. 2020; 25(1): 67-73, doi: 10.1007/s10741-019-09853-7, indexed in Pubmed: 31489515.

64. Kosmala W, Rojek A, Przewlocka-Kosmala M, et al. Contributions of nondiastolic factors to exercise intolerance in heart failure with preserved ejection fraction. J Am Coll Cardiol. 2016; 67(6): 659-670, doi: 10.1016/j.jacc.2015.10.096, indexed in Pubmed: 26868691.

65. Przewlocka-Kosmala M, Marwick TH, Dabrowski A, et al. Contribution of cardiovascular reserve to prognostic categories of heart failure with preserved ejection fraction: a classification based on machine learning. J Am Soc Echocardiogr. 2019; 32(5): 604-615.e6, doi: 10.1016/j.echo.2018.12.002, indexed in Pubmed: 30718020.

66. Barandiarán Aizpurua A, Sanders-van Wijk S, Brunner-La Rocca HP, et al. Validation of the HFA-PEFF score for the diagnosis of heart failure with preserved ejection fraction. Eur J Heart Fail. 2020; 22(3): 413-421, doi: 10.1002/ejhf.1614, indexed in Pubmed: 31472035.

67. Oh JK, Miranda WR, Bird JG, et al. The 2016 diastolic function guideline: is it already time to revisit or revise them? JACC Cardiovasc Imaging. 2020; 13(1 Pt 2): 327-335, doi: 10.1016/j. jcmg.2019.12.004, indexed in Pubmed: 31918901.

68. Ouwerkerk W, Tromp J, Jin X, et al. Heart failure with preserved ejection fraction diagnostic scores in an Asian population. Eur J Heart Fail. 2020 [Epub ahead of print], doi: 10.1002/ejhf.1851, indexed in Pubmed: 32378225.

69. Tromp J, Teng TH, Tay WT, et al. ASIAN-HF Investigators. Heart failure with preserved ejection fraction in Asia. Eur J Heart Fail. 2019; 21(1): 23-36, doi: 10.1002/ejhf.1227, indexed in Pubmed: 30113120.

70. McHugh K, DeVore AD, Wu J, et al. Heart failure with preserved ejection fraction and diabetes: JACC state-of-the-art review. J Am Coll Cardiol. 2019; 73(5): 602-611, doi: 10.1016/j. jacc.2018.11.033, indexed in Pubmed: 30732715.

71. Lam CSP, Donal E, Kraigher-Krainer E, et al. Epidemiology and clinical course of heart failure with preserved ejection fraction. Eur J Heart Fail. 2011; 13(1): 18-28, doi: 10.1093/eurjhf/hfq121, indexed in Pubmed: 20685685.

72. Dunlay SM, Roger VL, Redfield MM. Epidemiology of heart failure with preserved ejection fraction. Nat Rev Cardiol. 2017; 14(10): 591-602, doi: 10.1038/nrcardio.2017.65, indexed in Pubmed: 28492288 .

73. Gerber Y, Weston SA, Redfield MM, et al. A contemporary appraisal of the heart failure epidemic in Olmsted County, Minnesota, 2000 to 2010. JAMA Intern Med. 2015; 175(6): 996-1004, doi: 10.1001/jamainternmed.2015.0924, indexed in Pubmed: 25895156.

74. Fukuma N, Takimoto E, Ueda K, et al. Estrogen receptor- $\alpha$ non-nuclear signaling confers cardioprotection and Is Essential to cGMP-PDE5 inhibition efficacy. JACC Basic Transl Sci. 2020; 5(3): 282-295, doi: 10.1016/j.jacbts.2019.12.009, indexed in Pubmed: 32215350 .

75. Barton M, Meyer MR. Heart Failure with preserved ejection fraction in women: new clues to causes and treatment. JACC Basic Transl Sci. 2020; 5(3): 296-299, doi: 10.1016/j. jacbts.2020.02.001, indexed in Pubmed: 32215378.

76. Sabbatini AR, Kararigas G. Menopause-Related estrogen decrease and the pathogenesis of HFpEF: JACC review topic of the week. J Am Coll Cardiol. 2020; 75(9): 1074-1082, doi: 10.1016/j. jacc.2019.12.049, indexed in Pubmed: 32138968.
77. Beale AL, Nanayakkara S, Segan L, et al. Sex differences in heart failure with preserved ejection fraction pathophysiology: a detailed invasive hemodynamic and echocardiographic analysis. JACC Heart Fail. 2019; 7(3): 239-249, doi: 10.1016/j. jchf.2019.01.004, indexed in Pubmed: 30819380.

78. Obokata M, Reddy YNV, Pislaru SV, et al. Evidence supporting the existence of a distinct obese phenotype of heart failure with preserved ejection fraction. Circulation. 2017; 136(1): 6-19, doi: 10.1161/CIRCULATIONAHA.116.026807, indexed in Pubmed: 28381470.

79. Reddy YNV, Lewis GD, Shah SJ, et al. Characterization of the obese phenotype of heart failure with preserved ejection fraction: a RELAX trial ancillary study. Mayo Clin Proc. 2019; 94(7): 1199-1209, doi: 10.1016/j.mayocp.2018.11.037, indexed in Pubmed: 31272568.

80. Zafrir B, Lund LH, Laroche C, et al. Prognostic implications of atrial fibrillation in heart failure with reduced, mid-range, and preserved ejection fraction: a report from 14964 patients in the European Society of Cardiology Heart Failure Long-Term Registry. Eur Heart J. 2018; 39(48): 4277-4284, doi: 10.1093/ eurheartj/ehy626, indexed in Pubmed: 30325423.

81. Sartipy U, Dahlström U, Fu M, et al. Atrial fibrillation in heart failure with preserved, mid-range, and reduced ejection fraction. JACC Heart Fail. 2017; 5(8): 565-574, doi: 10.1016/j. jchf.2017.05.001, indexed in Pubmed: 28711451.

82. Kirchhof P, Benussi S, Kotecha D, et al. ESC Scientific Document Group. 2016 ESC Guidelines for the management of atrial fibrillation developed in collaboration with EACTS. Eur Heart J. 2016; 37(38): 2893-2962, doi: 10.1093/eurheartj/ehw210, indexed in Pubmed: 27567408.

83. Dobrowolski P, Florczak E, Klisiewicz A, et al. Factors associated with diastolic dysfunction in patients with resistant hypertension: resist-POL study. Am J Hypertens. 2015; 28(3): 307-311, doi: 10.1093/ajh/hpu150, indexed in Pubmed: 25159084.

84. Bristow MR, Enciso JS, Gersh BJ, et al. Detection and Management of Geographic Disparities in the TOPCAT Trial: Lessons Learned and Derivative Recommendations. JACC Basic Transl Sci. 2016; 1(3): 180-189, doi: 10.1016/j.jacbts.2016.03.001, indexed in Pubmed: 27747305.

85. Cleland J, Tendera M, Adamus J. The perindopril in elderly people with chronic heart failure (PEP-CHF) study. Eur Heart J. 2006; 27(19): 2338-2345, doi: 10.1093/eurheartj/ehl250.

86. Kosmala W. Diagnosing HFpEF: On Track at Last? JACC Cardiovasc Imaging. 2018; 11(4): 586-588, doi: 10.1016/j. jcmg.2017.05.024, indexed in Pubmed: 28823738.

87. van Heerebeek L, Paulus WJ. Understanding heart failure with preserved ejection fraction: where are we today? Neth Heart J 2016; 24(4): 227-236, doi: 10.1007/s12471-016-0810-1, indexed in Pubmed: 26909795.

88. Ge J. Coding proposal on phenotyping heart failure with preserved ejection fraction: A practical tool for facilitating etiologyoriented therapy. Cardiol J. 2020; 27(1): 97-98, doi: 10.5603/ CJ.2020.0023, indexed in Pubmed: 32103486.

89. Tromp J, Tay WT, Ouwerkerk W, et al. Multimorbidity in patients with heart failure from 11 Asian regions: A prospective cohort study using the ASIAN-HF registry. PLoS Med. 2018; 15(3): e1002541, doi: 10.1371/journal.pmed.1002541, indexed in Pubmed: 29584721.

90. Shah S, Katz D, Selvaraj S, et al. Phenomapping for novel classification of heart failure with preserved ejection fraction. Circulation. 2015; 131(3): 269-279, doi: 10.1161/circulationaha.114.010637.

91. Samson R, Jaiswal A, Ennezat PV, et al. Clinical phenotypes in heart failure with preserved ejection fraction. J Am Heart Assoc. 2016; 5(1), doi: 10.1161/JAHA.115.002477, indexed in Pubmed: 26811159.

92. Michalski B, Trzciński P, Kupczyńska K, et al. The differences in the relationship between diastolic dysfunction, selected biomarkers and collagen turn-over in heart failure patients with preserved and reduced ejection fraction. Cardiol J. 2017; 24(1): 35-42, doi: 10.5603/CJ.a2016.0098, indexed in Pubmed: 27748500. 